\title{
Investigation of the effects of P1 on HC-pro-mediated gene silencing suppression through genetics and omics approaches
}

\author{
Sin-Fen Hu${ }^{1}$, Wei-Lun Wei ${ }^{1}$, Syuan-Fei Hong ${ }^{1}$, Ru-Ying Fang ${ }^{1}$, Hsin-Yi Wu ${ }^{4}$, Pin-Chun Lin ${ }^{1}$, Neda Sanobar ${ }^{1}$, \\ Hsin-Ping Wang ${ }^{1,5}$, Margo Sulistio ${ }^{5}$, Chun-Ta Wu ${ }^{5}$, Hsiao-Feng Lo ${ }^{5}$ and Shih-Shun Lin ${ }^{1,2,3^{*}}$ (]
}

\begin{abstract}
Background: Posttranscriptional gene silencing (PTGS) is one of the most important mechanisms for plants during viral infection. However, viruses have also developed viral suppressors to negatively control PTGS by inhibiting microRNA (miRNA) and short-interfering RNA (siRNA) regulation in plants. The first identified viral suppressor, P1/HC-Pro, is a fusion protein that was translated from potyviral RNA. Upon infecting plants, the P1 protein itself is released from HCPro by the self-cleaving activity of P1. P1 has an unknown function in enhancing HC-Pro-mediated PTGS suppression. We performed proteomics to identify P1-interacting proteins. We also performed transcriptomics that were generated from Col-0 and various P1/HC-Pro-related transgenic plants to identify novel genes. The results showed several novel genes were identified through the comparative network analysis that might be involved in P1/HC-Pro-mediated PTGS suppression.
\end{abstract}

Results: First, we demonstrated that P1 enhances HC-Pro function and that the mechanism might work through P1 binding to VERNALIZATION INDEPENDENCE 3/SUPERKILLER 8 (VIP3/SKI8), a subunit of the exosome, to interfere with the 5'-fragment of the PTGS-cleaved RNA degradation product. Second, the AGO1 was specifically posttranslationally degraded in transgenic Arabidopsis expressing P1/HC-Pro of turnip mosaic virus (TuMV) (P1/HC Tu plant). Third, the comparative network highlighted potentially critical genes in PTGS, including miRNA targets, calcium signaling, hormone (JA, ET, and ABA) signaling, and defense response.

Conclusion: Through these genetic and omics approaches, we revealed an overall perspective to identify many critical genes involved in PTGS. These new findings significantly impact in our understanding of P1/HC-Pro-mediated PTGS suppression.

Keywords: P1/HC-Pro, Viral suppressor, Posttranscriptional gene silencing, MicroRNA, Omics, Comparative network

\section{Background}

Posttranscriptional gene silencing (PTGS) includes the regulation of microRNA (miRNA) and short-interfering RNA (siRNA) in plant development. The DICER-LIKE 2 (DCL2)/DICER-LIKE 4 (DCL4)-mediated siRNA pathway is a major defense system that inhibits viral infection.

\footnotetext{
*Correspondence: linss01@ntu.edu.tw

1 Institute of Biotechnology, National Taiwan University, Taipei 106, Taiwan Full list of author information is available at the end of the article
}

However, different species of viruses have developed various suppressors to counteract the DCL2/4-mediated siRNA defense system, known as PTGS suppression, making these species capable of surviving and multiplying in the infected plants. Viral suppressors of PTGS not only suppress the siRNA defense system but also inhibit miRNA regulation, resulting in symptom development. Symptoms represent the misregulation of the miRNA phenomena, whereas a mutant virus has a defective suppressor that causes mild symptoms and has a limited 
inhibitory effect on miRNA-regulation (Kung et al. 2014; Wu et al. 2010).

Viral suppressors of PTGS have various approaches to interfere with miRNA biogenesis or miRNA regulation. For instance, $2 \mathrm{~b}$ of the cucumber mosaic virus (CMV) Q strain and p19 of tomato busy stunt virus (TBSV) binds miRNA and siRNA to prevent those of small RNAs loading into AGO1 (Silhavy et al. 2002; Zhang et al. 2006). P0 of polerovirus has an F-box-like domain to trigger AGO1 degradation (Michaeli et al. 2019). P1/HC-Pro is the first identified viral suppressor of PTGS (Anandalakshmi et al. 1998; Kasschau and Carrington, 1998). HC-Pro is a highly conserved protein in potyvirus that plays a major role in PTGS suppression (Kasschau and Carrington, 1998; Kasschau et al. 2003; Kung et al. 2014; Valli et al. 2006). In contrast, P1 is a highly divergent protein that has variable sequences in each potyvirus. $\mathrm{P} 1$ of tobacco etch virus (TEV) can enhance the HC-Pro-mediated PTGS suppression; however, the mechanism is still unclear (Kasschau and Carrington, 1998; Martínez and Daròs, 2014; Valli et al. 2006). Martinez and Daròs (2014) demonstrated that $\mathrm{P} 1$ of TEV interacts with the $60 \mathrm{~S}$ ribosomal subunit and enhances in vitro translation.

Previous studies demonstrated that P1/HC-Pro genes of zucchini yellow mosaic virus (ZYMV) and turnip mosaic virus (TuMV) suppressed miRNA regulation (Kung et al. 2014; Wu et al. 2010). Transgenic Arabidopsis expressing P1/HC-Pro of ZYMV (P1/HC $C^{Z y}$ plant) or P1/HC-Pro of TuMV (P1/HC $C^{T u}$ plant) showed severe serrated and curling leaf phenotypes that are related to miRNA misregulation and viral symptom development (Kung et al. 2014; Wu et al. 2010). Moreover, the FRNK motif (highly conserved amino acid sequence) of HCPro in TuMV and ZYMV is necessary and sufficient for PTGS suppression (Kung et al. 2014; Wu et al. 2010). The miRNA misregulation in transgenic plant expressing viral suppressor gene, such as $2 b, P 1 / H C$-Pro, and P19, is occurred by abnormal miRNA/miRNA* accumulation via an unknown mechanism, resulting in target RNA accumulation (Kasschau et al. 2003; Kung et al. 2014). Therefore, abnormal miRNA/miRNA* and target RNA accumulations are the molecular phenotypes of PTGS suppression.

In this study, we demonstrated that various potyviruses of P1 are necessary and sufficient to enhance HCPro PTGS suppression. Through high-throughput omics approaches, several critical genes that interact with P1 or are involved in PTGS were identified from immunoprecipitation (IP) and transcriptomic profiles. We also found that P1/HC-Pro of TuMV triggers Argonaute protein 1 (AGO1) posttranslational degradation. These critical genes offer new directions for further investigation of the PTGS and P1/HC-Pro-mediated suppression.

\section{Materials and methods}

\section{Plant material and transgenic plants}

Arabidopsis thaliana ecotype Col-0 and transgenic plants, $P 1 / H C^{T u}$ plant, and $P 1 / H C^{Z y}$ plant (Wu et al. 2010) were used in this study. Arabidopsis seeds were surface sterilized and chilled at $4{ }^{\circ} \mathrm{C}$ for 2 days and then sown on Murashige and Skoog (MS) medium with/without suitable antibiotics. The seedlings were transferred into soil after 1 week of germination. All plants were grown at $24{ }^{\circ} \mathrm{C}$ in a growth room with $16 \mathrm{~h}$ of light $/ 8 \mathrm{~h}$ of dark.

\section{Transgenic plant construction}

For $P 1 / H C^{T e}$ plant construction, the $P 1 / H C$-Pro gene of TEV was amplified from the pTEV-At17 plasmid (Agudelo-Romero et al. 2008) by polymerase chain reaction (PCR) with the primer set: PteP1 (5'-CACCAT GGCACTCATCTT-3') and MTEHC (5'-TCCAACATT GTAAGTTTT- $3^{\prime}$ ). The PCR fragment was cloned into the $\mathrm{pENTR/D-TOPO}$ vector (Invitrogen) to generate pENTR-P1/HC ${ }^{\mathrm{Te}}$. The pENTR vector was transferred into the pBCo-DC vector (Kung et al. 2014) using Gateway LR Clonase II Enzyme Mix (Thermo Fisher) to generate $\mathrm{pBCo}-\mathrm{P} 1 / \mathrm{HC}^{\mathrm{Te}}$.

For $P 1^{T u}$ plant construction, the TuMV infectious clone was used as a template to amplify the $P 1^{T u}$ gene with the primer set: PtuP1/MTuP1 (5'-TCAAAAGTGCACAAT CTT $\left.-3^{\prime}\right)$, and the gene was then cloned into the pENTR and $\mathrm{pBCo}-\mathrm{DC}$ vectors following the above procedures to generate $\mathrm{pBCo}-\mathrm{P} 1$. For the $H C^{T u}$ plant resistant to Basta, the TuMV infectious clone was used as template to amplify the $H C^{T u}$ gene with the primer set: PTuHC (5'CACCATGAGTGCAGCAGGAGCC- $\left.3^{\prime}\right) / \mathrm{MTuHC}$, and it was then cloned into the pENTR and pBCo-DC vectors following the above procedures to generate the $\mathrm{pBCo}-$ $\mathrm{HC}^{\mathrm{Tu}}$ fragment. An NheI site was introduced into the fusion form of the P1HC-Pro gene $\left(P 1 H C^{T u-F A}\right)$ to generate a $\mathrm{F}_{362} \mathrm{~A}$ substitution. Furthermore, the $\mathrm{P} 1$ and $\mathrm{HC}$-Pro genes were amplified from the TuMV infectious clone (Niu et al. 2006) and constructed under the 35S promoter to create the $P 1^{T u}$ and $H C^{T u}$ plants, respectively. The $\mathrm{pBCo}-\mathrm{P} 1 / \mathrm{HC}^{\mathrm{Te}}, \mathrm{pBCo}^{\mathrm{P}} 1^{\mathrm{Tu}}, \mathrm{pBCo}-\mathrm{HC}^{\mathrm{Tu}}$, and $\mathrm{pBCo}-$ $\mathrm{P} 1 \mathrm{HC}{ }^{\mathrm{Tu}-\mathrm{FA}}$ binary vectors were transferred into Col-0 by the floral-dipping method with the Agrobacterium tumefaciens ABI strain to generate the $P 1 / H C^{T e}, P 1^{T u}$, and $H C^{T u}$ plants, respectively.

For recombined P1/HC-Pro transgenic plant construction, the infectious clones of TuMV, ZYMV, and TEV were used as templates to generate the recombinant P1/HC-Pro constructs. The P1 cleavage site in the recombined gene had to be preserved in the recombined constructs, and the constructs were cloned into 
the pBCo binary vector (Kung et al. 2014) for Agrobacterium-mediated flower-dipping transformation.

\section{Antibody production}

For the TuMV P1 antibody, the N-terminus of the P1 (1-190 aa) of DNA fragment was amplified with the following primer sets PTuP1-NheI (5'-TATGGCTAGCAT GGCAGTAGTTACATTCGC-3')/MTuP1570-XhoI (5'GGTGCTCGAGGCTCGCAGAGAGTCCTCCTC-3'). For the ZYMV P1 antibody, the $\mathrm{N}$-terminus of the P1 (1-142 aa) DNA fragment was amplified with primer sets PZyP1- NheI (5'-TATGGCTAGCATGGCCTC AGTTATGATTGG-3')/MZy426-XhoI (5'-GGTGCT CGAGCACTTCAGGTGGAAGAACAC-3'). For the TEV P1 antibody, the N-terminus of the P1 (1-133 aa) DNA fragment was amplified with primer sets PTeP1NheI (5'-TATGGCTAGCATGGCACTCATCTTTGG CAC-3')/MTe399-XhoI (5'-GGTGCTCGAGATCAA CCTTTCTCTCGGTGT-3').

For the TuMV HC-Pro antibody, the internal region of the HC-Pro (1-103 aa) of DNA fragment was amplified with primer sets PTuHC-NheI (5'-TATGGCTAG CACAGGGGAGGAATTCTCACA-3')/MTuHC309XhoI (5'-GGTGCTCGAGGATTGCAAGTTTCCGTG ACC- $\left.3^{\prime}\right)$. For the ZYMV HC-Pro antibody, the internal region of the HC-Pro (1-87 aa) DNA fragment was amplified with primer sets PZyHC-NheI $\left(5^{\prime}\right.$-TAT GGC TAG CAC ACA GGC AAC TCAGAATCT-3')/ MZyHC261-XhoI (5'-GGTGCTCGAGAGGATTTA TCATAGCCTTGC- $3^{\prime}$ ). For the TEV HC-Pro antibody, the internal region of the HC-Pro (1-99 aa) DNA fragment was amplified with primer sets PTeHC-NheI (5'TATGGCTAGCACAGGGGCTGATCTCGAAGA- $\left.3^{\prime}\right)$ / MTeHC297-XhoI (5'-GGTGCTCGAGTCTGCTAC CCCTGATATGTT-3').

All of the PCR fragments were digested with NheI and $X h o I$ and then ligated with the same restriction enzyme-digested $\mathrm{pET}-28 \mathrm{a}$ vector to generate $\mathrm{pET}-\mathrm{P} 1^{\mathrm{Tu}}$, pET-P1 $1^{\mathrm{Zy}}$, pET-P1 ${ }^{\mathrm{Te}}$, pET-HC ${ }^{\mathrm{Tu}}, \mathrm{pET}-\mathrm{HC}^{\mathrm{Zy}}$, and pET$\mathrm{HC}^{\mathrm{Te}}$ ). All of the pET28 plasmids were transformed into the E. coli BL21 strain for recombinant protein expression. All recombinant proteins were purified by fast protein liquid chromatography (FPLC) (AKTApurifier, GE Healthcare). One milligram of recombinant protein with a $1 \times$ volume of complete Freund's adjuvant was injected into New Zealand white rabbits for the first injection. The following three injections consisted of $1 \mathrm{mg}$ of protein mixed with a $1 \times$ volume of incomplete Freund's adjuvant. IgG purification was performed according to the protocol of Chiu et al. (2013). The IgG was collected after 4 injections for western blot detection.

\section{Immunoprecipitation and in-solution protein digestion}

To identify the P1-interacting proteins, $250 \mathrm{mg}$ of 10-day-old seedlings $(n=6)$ were homogenized with $1 \mathrm{~mL}$ IP buffer [25 mM Tris- $\mathrm{HCl}, \mathrm{pH} 7.0,150 \mathrm{mM}$ $\mathrm{NaCl}, 1 \mathrm{mM}$ EDTA, 5\% glycerol, and a protease inhibitor (Roche)], followed by centrifugation for $10 \mathrm{~min}$ at $4{ }^{\circ} \mathrm{C}$. IgG of $\alpha-P 1^{\mathrm{Tu}}, \alpha-\mathrm{P} 1^{\mathrm{Zy}}$, and $\alpha-\mathrm{P} 1^{\mathrm{Te}}$ was used for the in vivo IP. IP was performed by mixing $30 \mu \mathrm{l}$ of washed Protein A Mag Sepharose ${ }^{\mathrm{TM}}$ Xtra ferrite beads (GE), IgG (30 $\mu \mathrm{l}$ per IP reaction) and lysate. The IP reaction was carried out at $4{ }^{\circ} \mathrm{C}$ with gentle mixing for $3 \mathrm{~h}$. The tube was then centrifuged at $300 \mathrm{~g}$ to pull-down the beads, which were washed three times with $0.3 \mathrm{~mL}$ wash buffer $(25 \mathrm{mM}$ Tris, $150 \mathrm{mM} \mathrm{NaCl}, 1 \mathrm{mM}$ EDTA, 5\% glycerol, 0.1\% Triton-X-100, and a protease inhibitor) to remove nonspecific binding. Finally, the beads were resuspended in 50 $\mu \mathrm{L}$ elution buffer ( $0.1 \mathrm{M}$ glycine, $\mathrm{pH} 2.0)$, and the reaction was mixed on a rotary at $4{ }^{\circ} \mathrm{C}$ for $10 \mathrm{~min}$. A total of $10 \mu \mathrm{L}$ of neutralization buffer (Tris- $\mathrm{HCl}, \mathrm{pH} 8.0$ ) was added to neutralize the reaction.

The proteins were dissolved in $6 \mathrm{M}$ urea. A total of $15 \mu \mathrm{g}$ of protein from each time point was used for insolution digestion. Proteins were reduced by incubation with $10 \mathrm{mM}$ dithiothreitol (DTT) for $1 \mathrm{~h}$ at $29^{\circ} \mathrm{C}$ and alkylated by $55 \mathrm{mM}$ iodoacetamide (IAA) at room temperature for $1 \mathrm{~h}$. This step was quenched by $55 \mathrm{mM}$ DTT at $29^{\circ} \mathrm{C}$ for $45 \mathrm{~min}$. The concentration of urea was diluted to $1 \mathrm{M}$ before the sample was subjected to proteolysis. Protein digestion was performed overnight at $29^{\circ} \mathrm{C}$ using mass spectrometry-grade modified trypsin (Promega) at a 1:50 trypsin/protein ratio. After overnight incubation, $0.1 \%$ TFA was added to stop the digestion. Finally, all remaining reagents from the in-solution digestion procedure were removed using a $\mathrm{C} 18$ stage tip.

\section{LC-MS/MS analysis}

High-performance liquid chromatography with tandem mass spectrometry (LC-MS/MS) was performed on an Orbitrap Fusion Lumos Tribrid quadrupole-ion trap mass spectrometer (Thermo Fisher Scientific) in the Instrumentation Center of National Taiwan University. Peptides were separated on an Ultimate System 3000 NanoLC System (Thermo Fisher Scientific). Peptide mixtures were loaded onto a $75 \mu \mathrm{m}$ inner diameter (ID), $25 \mathrm{~cm}$ length C18 Acclaim PepMap NanoLC column (Thermo Scientific) packed with $2 \mu$ m particles with a pore size of $100 \AA$. Mobile phase A was $0.1 \%$ formic acid in water, and mobile phase B was $100 \%$ acetonitrile with $0.1 \%$ formic acid. A segmented gradient was set over $90 \mathrm{~min}$ from $2 \%$ to $35 \%$ solvent $\mathrm{B}$ at a flow rate of $300 \mathrm{nl} /$ min. Mass spectrometry analysis was performed in a data-dependent mode with full-MS (externally calibrated 
to a mass accuracy of $<5 \mathrm{ppm}$, and a resolution of 120,000 at $m / z=200$ ), followed by high-energy collision activated dissociation (HCD)-MS/MS of the most intense ions in $3 \mathrm{~s}$. HCD-MS/MS (resolution of 15,000) was used to fragment multiply charged ions within a $1.4 \mathrm{Da}$ isolation window at a normalized collision energy of 32. An automatic gain control (AGC) target at 5e 5 and $5 \mathrm{e} 4$ was set for MS and MS/MS analysis, respectively, with previously selected ions dynamically excluded for $180 \mathrm{~s}$. The max injection time was $50 \mathrm{~ms}$.

\section{Identification and quantitation of the proteome by label-free labeling methods}

Quantitative proteomics was performed by label-free quantitative proteomic analysis. The raw MS/MS data were searched against the UniProt Knowledgebase/ Swiss-Prot Arabidopsis thaliana protein database (Mar 2019 version) by using the Mascot 2.3 search algorithm via the Proteome Discoverer (PD) package (version 2.2, Thermo Scientific). The search parameters were set as follows: peptide mass tolerance, $10 \mathrm{ppm}$; MS/MS ion mass tolerance, $0.02 \mathrm{Da}$; enzyme set as trypsin and allowance of up to two missed cleavages; and variable modifications including oxidation on methionine, deamidation on asparagine and glutamine residues, and carbamidomethylation of cysteine residues. Peptides were filtered based on a $1 \%$ FDR. Protein quantification was computed by the abundance of ions extracted from the MS spectra of the corresponding peptides. The normalization method was set to the total peptide amount.

\section{Whole-transcriptome analysis}

Total RNAs that were isolated from 10-day-old seedlings of Col-0, $P 1^{T u}, H C^{T u}$, and $P 1 / H C^{T u}$ plants $(n=3)$ were used for whole-transcriptome deep sequencing by the High Throughput Sequencing Core of Academia Sinica. The sequencing was accomplished by paired-end $(2 \times 125)$ strand-specific HiSeq sequencing (Illumina). The transcriptome was analyzed by the ContigViews system (www.contigviews.bioagri.ntu.edu.tw) of the NGS core of National Taiwan University. For the ContigViews network analysis in this study, the twofold differentially expressed genes (DEGs) between Col-0 and P1/HC ${ }^{T u}$ plants $(n=3)$ with an $80 \%$ passing rate were selected for the assay. Reads with twofold $\log _{10}$ FPKM values of genes under 1.14 were trimmed. At least 10 samples from Col$0, P 1^{T u}, H C^{T u}$, and $P 1 / H C^{T u}$ profiles $(n=3)$ were selected to calculate the Pearson correlation with a 0.95 threshold for positive relation and a 0.9 threshold for negative relation. Notable, parameter determination is according to the highlighted genes and network complexity. These parameters can generate the best network for data mining in ContigViews.

\section{Ethylene detection}

Three-week-old Col- 0 and $P 1 / H C^{T u}$ plants $(n=3)$ were individually sealed in the $1.5 \mathrm{~L}$ chambers at $24{ }^{\circ} \mathrm{C}$ with $16 \mathrm{~h}$ light $/ 8 \mathrm{~h}$ dark. Ethylene gas samples in $(1 \mathrm{~mL})$ were withdrawn and collected at 4, 24, 48, and $72 \mathrm{~h}$ and were analyzed by GC-8A gas chromatography (Shimadzu) equipped with a flame ionization detector (FID).

\section{Results}

P1 enhances the severity of the HC-Pro-mediated serrated leaf phenotype and PTGS suppression

To dissect the function of $P 1^{T u}$ and $P 1 / H C^{T u}$ in PTGS suppression, we generated Arabidopsis transgenic lines expressing $P 1^{T u}$ and $P 1 / H C^{T u}$ in combinations or individually (Fig. 1a, b). The $P 1 / H C^{T u}$ plants showed a severe serrated and curled leaf phenotype (Fig. 1b, panel ii). The translated P1/HC-Pro protein contains an $\mathrm{F}_{362} / \mathrm{S}_{363}$ cleavage site (Fig. 1a), which can generate separated P1 and HC-Pro proteins through P1 cleavage (Fig. 1c). The $P 1^{T u}$ plant showed normal development similar to that of the Col-0 plants, whereas the $H C^{T u}$ plant showed mildly serrated leaves (Fig. 1b, panels iii and iv). In addition to the difference in the severity of the leaf phenotype, the size of the $H C^{T u}$ plant was larger than that of the $P 1 / H C^{T u}$ plant (Fig. 1b, panels ii and iv).

In addition, an $\mathrm{F}_{362} \mathrm{~A}$ substitution at the $\mathrm{F}_{362} / \mathrm{S}_{363} \mathrm{P} 1$ cleavage site produced a P1HC-Pro fusion protein $\left(\mathrm{P} 1 \mathrm{HC}^{\mathrm{Tu}-\mathrm{FA}}\right.$ ) (Fig. 1a, c). This transgenic P1HC ${ }^{T u-F A}$ plant showed a normal phenotype (Fig. 1b, panel v). Furthermore, a kanamycin-resistant $H C^{T u}$ plant $\left[H C^{T u}\right.$ (kan) plant] was generated for crossing with the $P 1^{T u}$ plant (Basta resistant) (Fig. 1a). Similar to the $H C^{T u}$ plant, the $H C^{T u}$ (kan) plant showed mildly serrated leaves (Fig. 1b, panel vi). Interestingly, the $P 1^{T u} \times H C^{T u(K a n)}$ offspring showed severely serrated and curled leaves, but the $P 1^{T u} \times H C^{T u}$ (Kan) plant was larger than that of the $P 1 / H C^{T u}$ plant (Fig. 1b, panel vii). In addition, only the $P 1 / H C^{T u}$ plant showed high levels of the P1 and HC-Pro proteins, while the other lines, even the $P 1^{T u} \times H C^{T u(K a n)}$ plant, showed low levels of P1 and HC-Pro (Fig. 1c).

We compared 57 potyvirus amino acid sequences of P1/HC-Pro (Fig. 2a). The alignment results showed that the sequence and length of the P1 protein in different potyviruses are highly diverse (Fig. 2a). Only the C-terminal protease activity site (black boxes) is conserved (Fig. 2a). In contrast, several conserved domains of HC-Pro were found in different species (Fig. 2a). To test whether the P1/HC-Pro from other potyviruses also induce serrated leaf phenotype, we generated Arabidopsis transgenic lines expressing P1/HC-Pro form ZYMV and TEV. $P 1 / H C^{Z y}$ plants showed a severe serrated and curled leaf phenotype, whereas P1/ $H C^{T e}$ plants showed a minor serrated leaf phenotype 
a

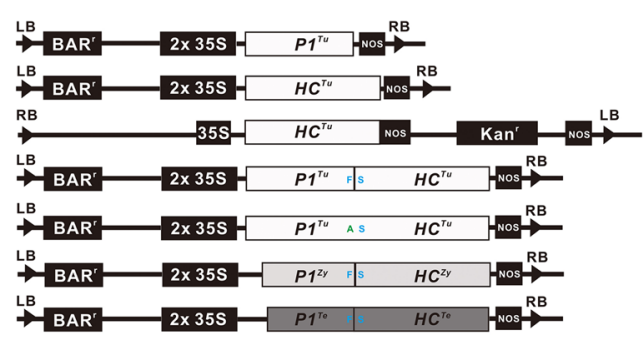

b
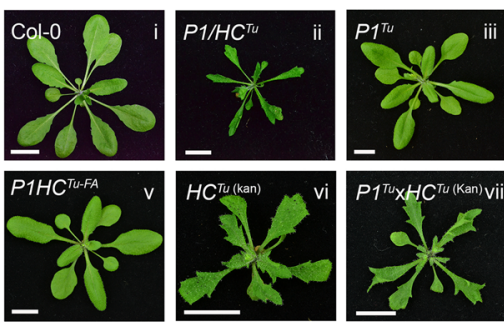

Plasmid

pBCo-P1 ${ }^{\text {Tu }}$

Protein

p101-HC ${ }^{\text {Tu }} \quad \mathrm{HC}^{\text {Tu (kan) }}$

pBCo-P1/HC ${ }^{\text {Tu }} \quad \mathrm{P} 1 / \mathrm{HC}^{\mathrm{Tu}}$

pBCo-P1HC Tu.FA $P 1 \mathrm{HC}^{\text {Tu.FA }}$

pBCo-P1/HC ${ }^{2 y} \quad \mathrm{P} 1 / \mathrm{HC}^{2 y}$

pBCo-P1/HC ${ }^{\text {Te }} \quad \mathrm{P} 1 / \mathrm{HC}^{\mathrm{Te}}$

C

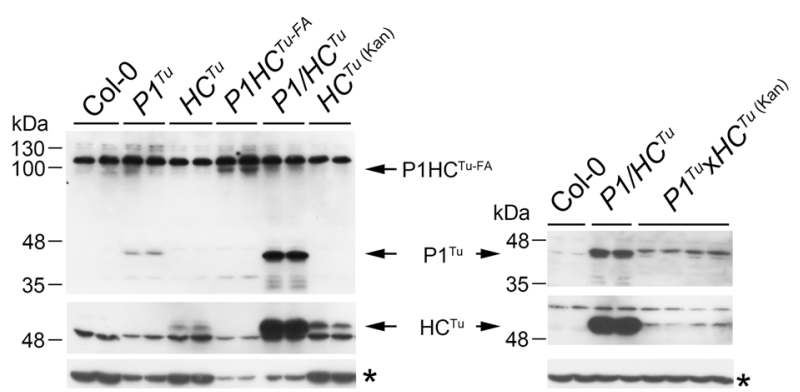

Fig. 1 P1 enhances the $H C^{T u}$-mediated phenotype and $H C^{T u}$ suppression in miRNA-mediated regulation. a Schematic binary plasmids containing the various constructs that were used in this study. $\mathbf{b}$ Phenotypes of the different transgenic plants. The photographs were taken of 3-week-old seedlings. Bar, $1 \mathrm{~cm}$. c Detection of P1 and HC-Pro of TuMV in various transgenic plants by western blotting. The asterisk (tubulin) is an internal control

(Fig. 2b). However, both plants had high levels of P1 and HC-Pro (Fig. 2c). The results indicated that the P1/ HC-Pro genes of ZYMV and TEV can also trigger a serrated leaf phenotype.

The next question was whether the function of the HC-Pro from each virus requires the P1 from the same species. We generated 6 recombinant P1/HC-Pro plants in which HC-Pro was fused with a heterologous P1, namely, $P 1^{Z y} / H C^{T u}, P 1^{T e} / H C^{T u}, P 1^{T u} / H C^{Z y}, P 1^{T e} /$ $H C^{Z y}, P 1^{T u} / H C^{T e}$, and $P 1^{Z y} / H C^{T e}$ (Fig. 2d). Except for $P 1^{T u} / H C^{T e}$ plants that show serrated leaves, the other 5 recombinant transgenic plants showed a severe serrated and curled leaf phenotype (Fig. 2e). The represented plants, $P 1^{Z y} / H C^{T u}$ and $P 1^{T e} / H C^{T u}$ plants, showed detectable P1 and HC-Pro expression (Fig. 2c). These results suggest that multiple $P 1$ genes have conserved functions in enhancing the HC-Pro-mediated serrated leaf phenotype.

\section{HC-Pro-mediated PTGS suppression}

Previous studies demonstrated that an abnormal accumulation of miRNA and miRNA* occurs in several transgenic viral suppressor plants because suppressors interfere with miRNA biogenesis (Kasschau et al. 2003; Kung et al. 2014; Wu et al. 2010). Indeed, $P 1 / H C^{T u}, P 1 /$ $H C^{Z y}, P 1 / H C^{T e}$, and 6 recombinant P1/HC-Pro plants showed abnormal miRNA/miRNA* accumulation (Fig. 2f). These data suggested that 3 species of viral P1/ HC-Pro and recombinant P1/HC-Pro interfered with miRNA biogenesis. In addition, except for the $P 1 H C^{T u-}$ ${ }^{F A}$ plant, all transgenic lines that contained $\mathrm{HC}^{\mathrm{Tu}}$ showed abnormal miRNA and miRNA* accumulation (Fig. 3a), confirming that $\mathrm{HC}^{\mathrm{Tu}}$ is the dominant player in PTGS suppression. Surprisingly, the $P 1^{T u}$ plant also showed miRNA and miRNA* accumulation through an unknown mechanism (Fig. 3a). In addition to miRNA/miRNA* accumulation, miRNA targets were also upregulated in 

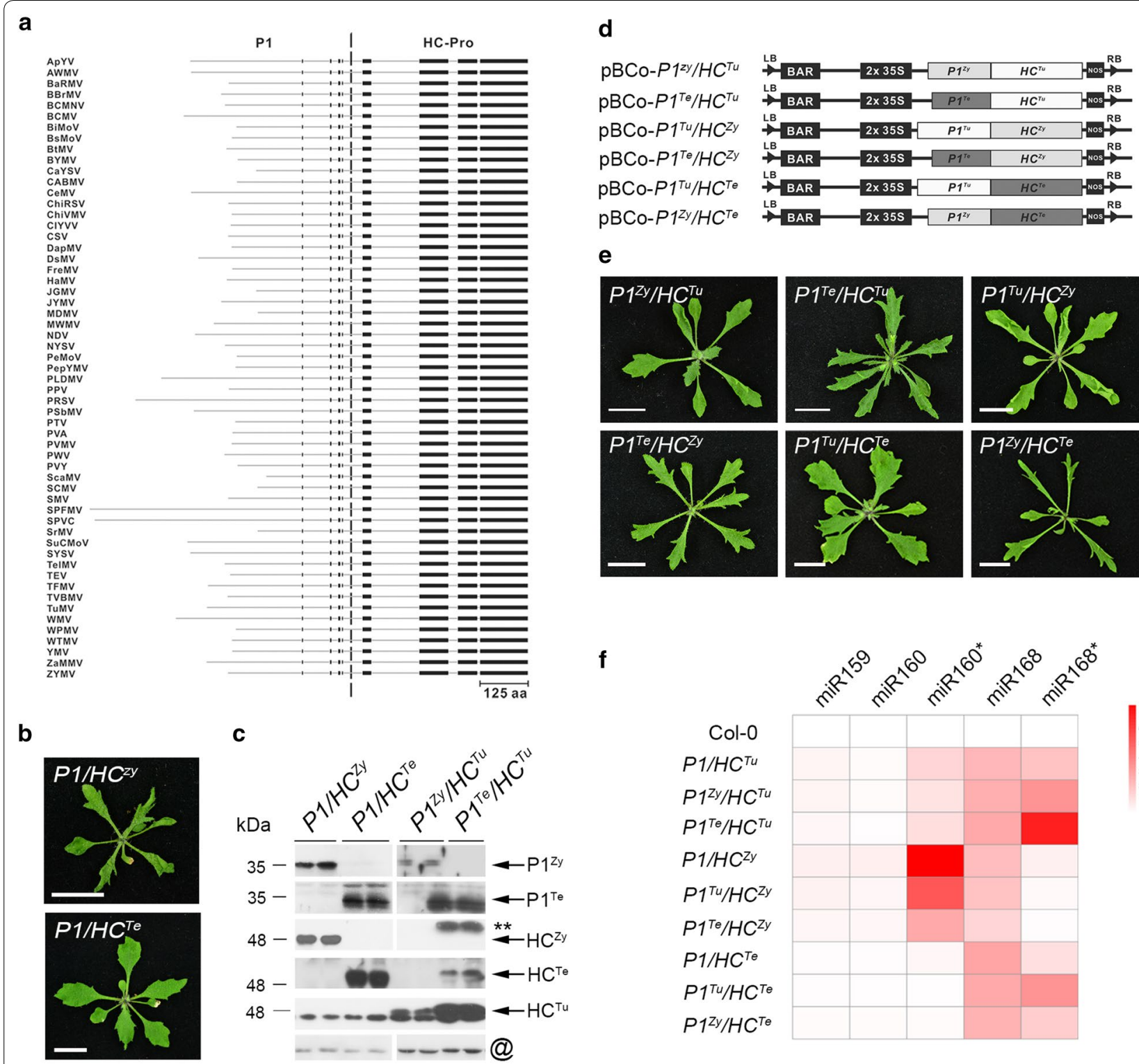

e
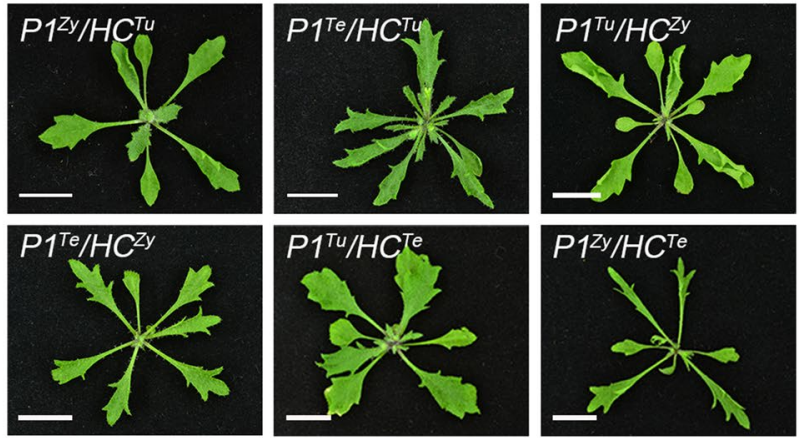

f

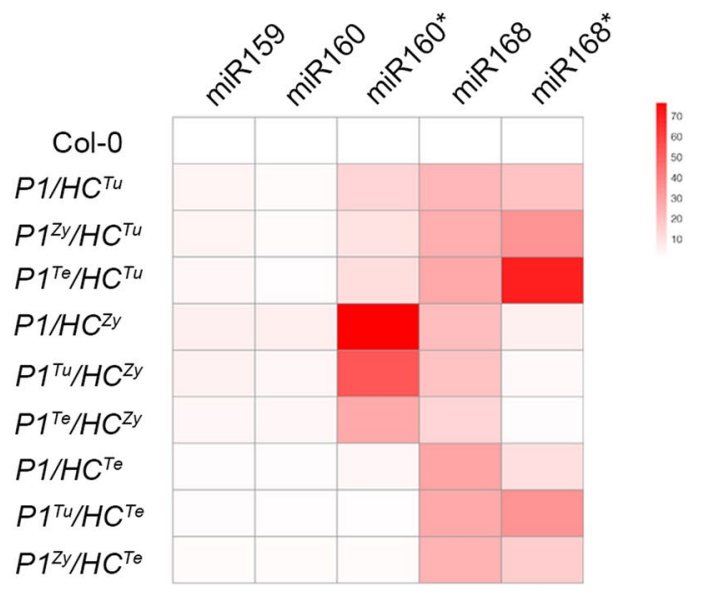

Fig. 2 Variation in potyvirus P1/HC-Pro and recombined P1/HC-Pro plants. a Schematic diagram of P1 and HC-Pro amino acid sequence similarity among fifty-seven Potyviruses. The black boxes indicate conserved sequence regions. b The morphologic phenotype of $P 1 / H C^{Z y}$ and $P 1 / H C^{T e}$ plants. Bar, 1 cm. c. Detection of P1 and HC-Pro in P1/HC $\mathrm{Zy}, P 1 / H C^{T e}, P 1^{2 y} / H C^{T u}$, and $P 1^{T e} / H C^{T u}$ plants. The @ symbol indicates CDC2 as an internal control. Two-asterisk $\left(^{* *}\right)$ indicate cross-reaction of the $\mathrm{a}-\mathrm{HC}^{\mathrm{Zy}}$ antibodies. $\mathbf{d}$ Schematic of the binary plasmids containing the various recombined $\mathrm{P} 1 /$ HC-Pro constructs used in this study. e Phenotypes of various recombinant P1/HC-Pro transgenic plants. The photographs were taken of 3-week-old seedlings. Bar, $1 \mathrm{~cm}$. $\mathbf{f}$ Heatmap of abnormal miRNA and miRNA* accumulation in various recombinant P1/HC-Pro plants. The values of heatmap were convert from miRNA northern blot. Significant upregulation (Student's $t$ test; $P$ value $<0.05$ ) is labeled in red. Gray indicates differential expression that is not significant. The values on the right indicate the results of the $\log _{2}$ (each sample/Col-0) formula

the transgenic plants because of miRNA misregulation (Kasschau et al. 2003; Kung et al. 2014; Wu et al. 2010). Transcriptome profiles also indicated that miRNA targets were upregulated in $H C^{T u}, H C^{T u}$ (kan),$P 1^{T u} \times H C^{T u}$, and $P 1 / H C^{T u}$ plants (Fig. 3b), suggesting that miRNA regulation was blocked by HC-Pro. However, DICER-LIKE 1 (DCL1; miR162 target) and two translation inhibition genes, APETALA 2 (AP2; miR172 target) and SHORT VEGETATIVE PHASE (SVP; miR396 target), showed no change in their transcript levels (Fig. 3b). Except for the DCL1, AP2, and SVP genes, the P1/HC Tu plant suppressed most of the miRNA-target regulation (Fig. 3b). We conclude that the $P 1 / H C^{T u}$ plant has a stronger suppressive effect than the $H C^{T u}$ plants. In addition, the 


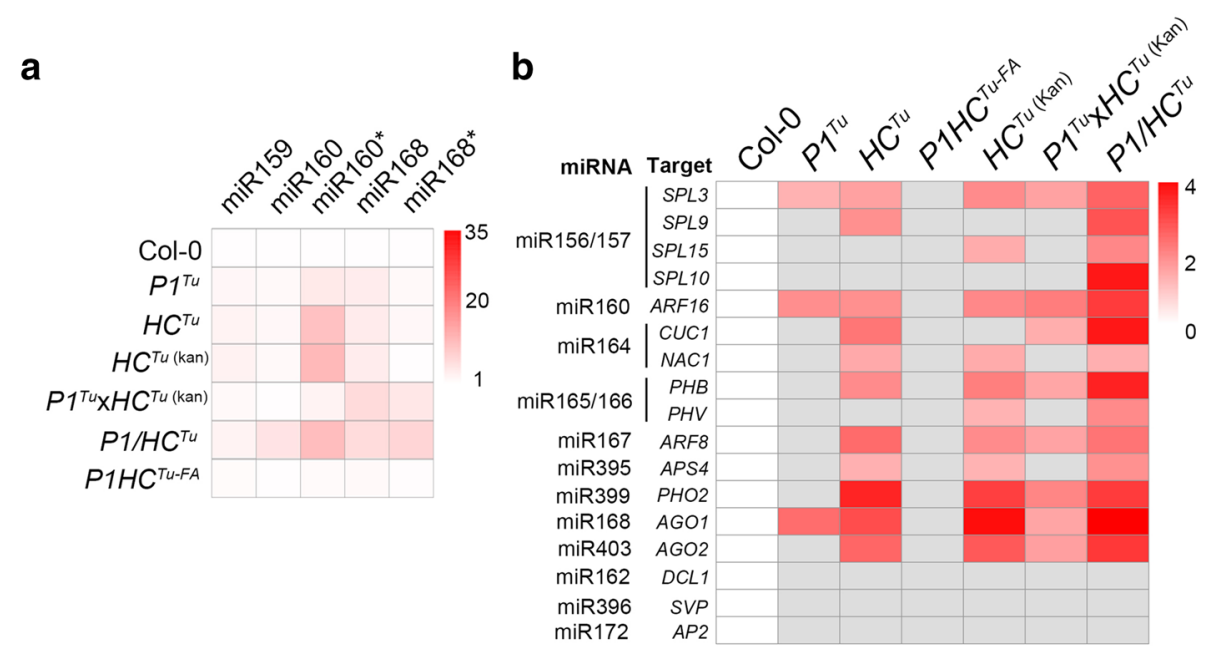

Fig. 3 Abnormal accumulation of miRNA/miRNA*s and target mRNAs. a Heatmaps of miRNA and miRNA* and $\mathbf{b}$ miRNA target gene expression in various transgenic plants. The values of heatmap for miRNA were convert from miRNA northern blot. The values of heatmap for target RNAs were convert from transcriptome profiles. Significant upregulation (Student's $t$ test; $P$ value $<0.05$ ) is labeled in red. Gray indicates differential expression that is not significant. The values on the right indicate the results of the $\log 2$ (each sample/Col-0) formula

heterologous P1s have conserved function(s) in enhancing HC-Pro-mediated PTGS suppression.

\section{Host P1-interacting proteins are involved in PTGS}

Because the recombinant P1/HC-Pro plants showed identical serrated leaf phenotypes and heterologous P1s could enhance HC-Pro-mediated PTGS suppression, we hypothesize that various $\mathrm{P} 1$ proteins have (a) conserved interacting protein(s) in Arabidopsis that enhance HCPro-mediated PTGS suppression. To identify the host P1-interacting proteins, the $P 1 / H C^{T u}, P 1 / H C^{Z y}$, and $P 1 /$ $H C^{T e}$ plants were used for IP with $\alpha-\mathrm{P} 1^{\mathrm{Tu}}, \alpha-\mathrm{P} 1^{\mathrm{Zy}}$, and $\alpha-P 1^{\mathrm{Te}}$ antibodies, respectively. These IP eluates were analyzed by LC-MS/MS. We identified 101 cytoplasmic $\mathrm{P} 1$ of TuMV $\left(\mathrm{P} 1^{\mathrm{Tu}}\right)$-interacting proteins (Additional file 1: Data). Furthermore, we identified 56 cytoplasmic $\mathrm{P} 1$ of ZYMV $\left(\mathrm{P}^{\mathrm{Zy}}\right)$-interacting proteins and 20 cytoplasmic P1 of TEV $\left(\mathrm{P} 1^{\mathrm{Te}}\right.$ )-interacting proteins (Additional file 1: Data). Importantly, only one consensus cytoplasmic protein, VERNALIZATION INDEPENDENCE 3/ SUPERKILLER8 (VIP3/SKI8; AT4G29830), was found in the IP profiles of 3 viral P1s (Table 1). VIP3/SKI8 is a subunit of the RNA exosome complex that is required for degradation of the RISC 5 -cleavage fragment (Branscheid et al. 2015; Orban and Izaurralde 2005). In contrast, 12 consensus cytoplasmic proteins were identified in the $\mathrm{P} 1^{\mathrm{Tu}}$ and $\mathrm{P} 1^{\mathrm{Zy}}$ IP profiles, whereas 10 consensus proteins were identified in the $\mathrm{P} 1^{\mathrm{Tu}}$ and $\mathrm{P} 1^{\mathrm{Te}}$ IP profiles (Table 1 ). Moreover, 5 consensus cytoplasmic proteins were found in the $\mathrm{P} 1^{\mathrm{Zy}}$ and $\mathrm{P} 1^{\mathrm{Te}} \mathrm{IP}$ profiles (Table 1).
Next, we focused on $\mathrm{P} 1^{\mathrm{Tu}}$-interacting proteins because the $P 1 / H C^{T u}$ plant was the model used in this study. In the $\mathrm{P} 1{ }^{\mathrm{Tu}}$ IP profile, two TUDOR-SN ribonucleases [(TSN1 (AT5G07350) and TSN2 (AT5G61780)] were uniquely identified 5 to 6 times in a total of 6 IP experiments with $P 1 / H C^{T u}$ plants (Table 1 , and Additional file 2: Table S1). TSN1 and TSN2 have been suggested to be involved in the regulation of uncapping mRNA and localize to processing bodies (P-bodies) and stress granules (Yan et al. 2014). Therefore, whether $\mathrm{P} 1{ }^{\mathrm{Tu}}$ could alter the function of TSN1 and TSN2 is an interesting project for the further investigation. Moreover, VARICOSE (VSC; AT3G13300) and MODIFIER OF SNC1,4 (MOS4; AT3G18165), which are involved in $\mathrm{RNA}$ regulation, were identified in the $\mathrm{P} 1^{\mathrm{Tu}}$ IP profile (Table 1 and Additional file 2: Table S1). We also identified the NUCLEAR-PORE ANCHOR (NUA; AT1G79280), two IMPORTIN subunits (AT5G53480 and AT4G16143), and BREFELDIN A-INHIBITED GUANINE NUCLEOTIDE-EXCHANGE PROTEIN 5 (BIG5; AT3G43300), which are involved in protein or nucleic acid transport between the nucleus and cytosol (Table 1 and Additional file 2: Table S1) (Xue et al. 2019). Moreover, VACUOLAR PROTEIN SORTINGASSOCIATED PROTEIN 29 (VSP29; AT3G47810) was identified, which participates in vacuolar protein trafficking and vacuolar sorting receptor recycling (Table 1 and Additional file 2: Table S1) (Kang et al. 2012). 
Table 1 The $\mathrm{P} 1$ interacting proteins

\begin{tabular}{|c|c|c|c|c|c|}
\hline \multirow[t]{2}{*}{ AGI } & \multirow[t]{2}{*}{ Protein name } & \multirow[t]{2}{*}{ Description } & \multicolumn{3}{|c|}{ Interacting with } \\
\hline & & & $\mathrm{P}^{\mathrm{Tu}}$ & $P 1^{Z y}$ & $\mathrm{P} 1^{\mathrm{Te}}$ \\
\hline AT4G29830 & VIP3/SKI8 & WD repeat-containing protein & $+^{a}$ & + & + \\
\hline AT5G61780 & TSN2 & Ribonuclease TUDOR 2 & + & & \\
\hline AT5G07350 & TSN1 & Ribonuclease TUDOR 1 & + & & \\
\hline AT3G13300 & VSC & Varicose & + & & \\
\hline AT2G15430 & DdRp & DNA-directed RNA polymerases subunit 3 & + & & \\
\hline AT3G18165 & MOS4 & Modifier of SNC1,4 & + & & \\
\hline AT1G79280 & NUA & Nuclear-pore anchor (NUA) & + & & \\
\hline AT5G53480 & Importin & Importin subunit beta-1 & + & & \\
\hline AT4G16143 & Importin & Importin subunit alpha-2 & + & & \\
\hline AT3G43300 & BIG5 & Brefeldin A-inhibited guanine nucleotide-exchange protein 5 & + & & \\
\hline AT3G47810 & VSP29 & Vacuolar protein sorting-associated protein 29 & + & & \\
\hline AT5G24780 & VSP1 & Vegetative storage protein 1 & + & + & \\
\hline AT1G52400 & & Beta-D-glucopyranosyl abscisate beta-glucosidase & + & + & \\
\hline AT1G53310 & & Phosphoenolpyruvate carboxylase 1 & + & + & \\
\hline AT1G16460 & & Thiosulfate/3-mercaptopyruvate sulfurtransferase 2 & + & + & \\
\hline AT3G27300 & & Glucose-6-phosphate 1-dehydrogenase, cytoplasmic isoform 1 & + & + & \\
\hline AT2G23930 & & Probable small nuclear ribonucleoprotein $\mathrm{G}$ & + & + & \\
\hline AT2G31390 & & Probable fructokinase-1 & + & + & \\
\hline AT3G62830 & & UDP-glucuronic acid decarboxylase 2 & + & + & \\
\hline AT5G03630 & & Monodehydroascorbate reductase 2 & + & + & \\
\hline AT3G52560 & & Ubiquitin-conjugating enzyme E2 variant 1D & + & + & \\
\hline AT1G64520 & & 265 proteasome non-ATPase regulatory subunit 8 homolog A & + & + & \\
\hline AT1G08830 & SOD1 & Superoxide dismutse [Cu-Zn] 1 & + & & + \\
\hline AT3G55620 & & Eukaryotic translation initiation factor $6-2$ & + & & + \\
\hline AT5G41220 & GST & Glutathione S-transferase T3 & + & & + \\
\hline AT4G24190 & & Endoplasmin homolog & + & & + \\
\hline AT5G42980 & & Thioredoxin $\mathrm{H} 3$ & + & & + \\
\hline AT1G72730 & & Eukaryotic initiation factor $4 \mathrm{~A}-3$ & + & & + \\
\hline AT1G77760 & & Nitrate reductase $[\mathrm{NADH}] 1$ & + & & + \\
\hline AT1G78370 & GST & Glutathione S-transferase U20 & + & & + \\
\hline AT3G61220 & & (+)-neomenthol dehydrogenase & + & & + \\
\hline AT3G06650 & & ATP-citrate synthase beta chain protein 1 & & + & + \\
\hline AT5G49460 & & ATP-citrate synthase beta chain protein 2 & & + & + \\
\hline AT5G44316 & & Putative UPF0051 protein ABC19 & & + & + \\
\hline AT3G44300 & & Nitrilase 2 & & + & + \\
\hline
\end{tabular}

a The protein was identified in the relevant P1 transgenic plants and marked as " $+"$

P1 and HC-Pro cause differentially expressed host proteins in transgenic plants

We performed label-free proteomics to identify the differentially expressed host proteins between Col-0 and other transgenic plants. We identified 2757 Arabidopsis proteins in Col-0, $P 1^{T u}, H C^{T u}$, and $P 1 / H C^{T u}$ plants (Additional file 1: Data). We found that ADP-GLUCOSE PYROPHOSPHORYLASE (APL3; AT4G39210), 6-PHOSPHOGLUCONOLACTONASE (PGL5; AT5G24420), and TONSOKU (TSK)-ASSOCIATING
PROTEIN 1 (TSA1; AT1G52410) were decreased in $P 1^{T u}$ and $P 1 / H C^{T u}$ plants compared to Col-0 plants but not decreased in $H C^{T u}$ plants (Fig. 4a-c, panel i). However, the transcript of APL3 showed no significant difference among the various transgenic plants, whereas PGL5 and TSA1 were upregulated in $H C^{T u}$ and $P 1 / H C^{T u}$ plants compared with Col-0 plants (Fig. $4 \mathrm{a}-\mathrm{c}$, panel ii). APL3 is a starch biosynthesis enzyme, whereas PGL5 is a catalyzed enzyme in the oxidative pentose-phosphate pathway (OPPP) (Lansing et al. 2020; Liu et al. 2019). TSA1 
a
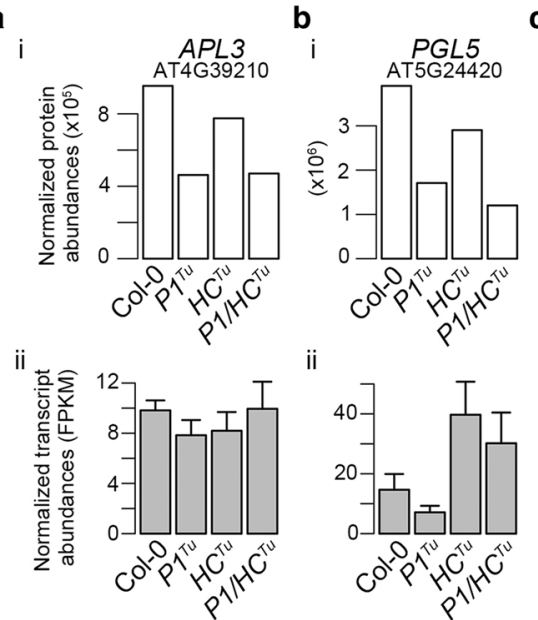

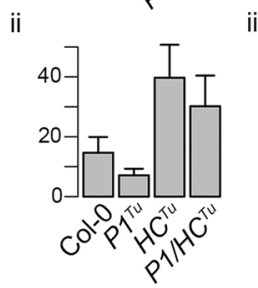

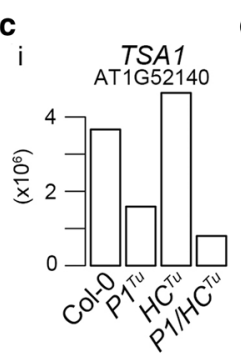

ii

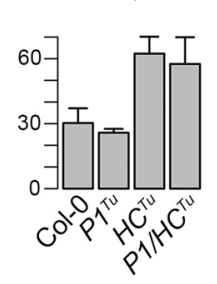

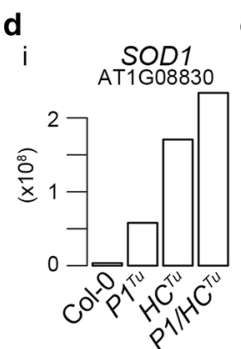

"
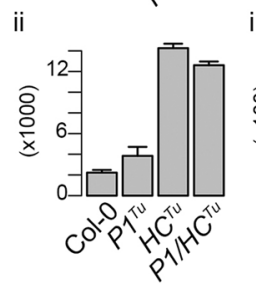

$\mathbf{e}_{\mathrm{i}}^{\mathrm{SOCD2} 28190} \mathrm{f}_{\mathrm{i}}^{\mathrm{S}}$

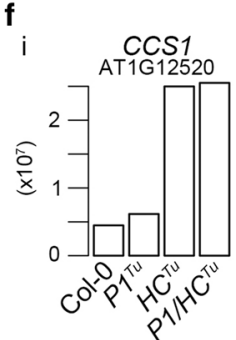

ii

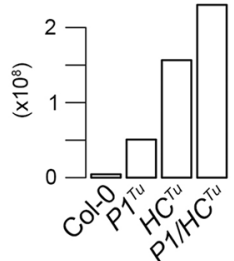

ii

ii
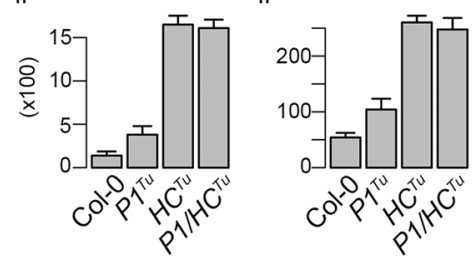

g
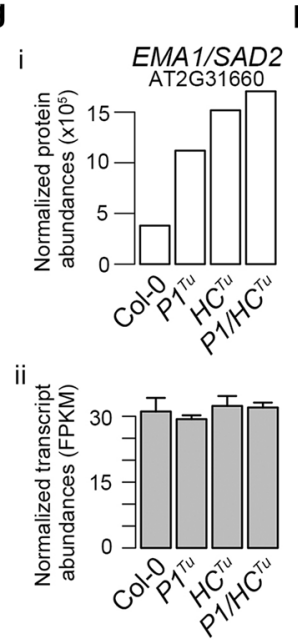

h
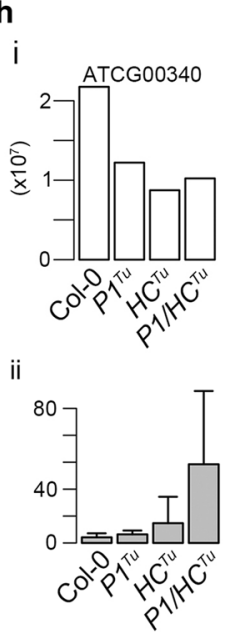
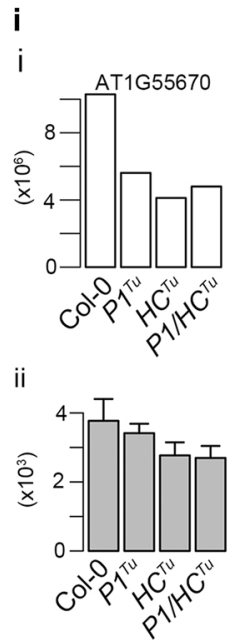
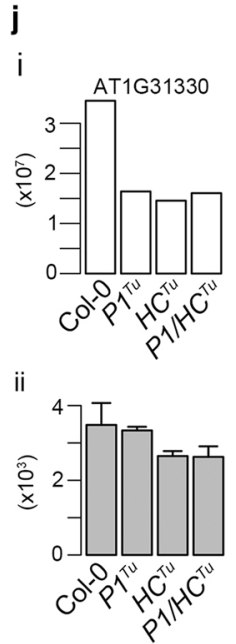
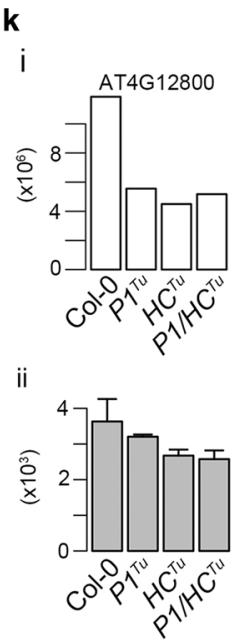

i
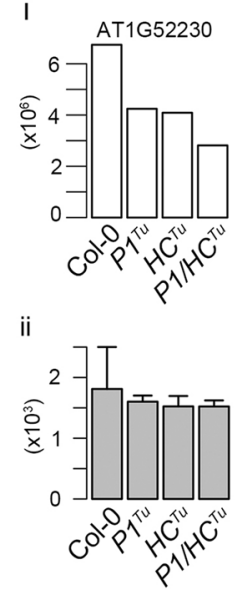

m
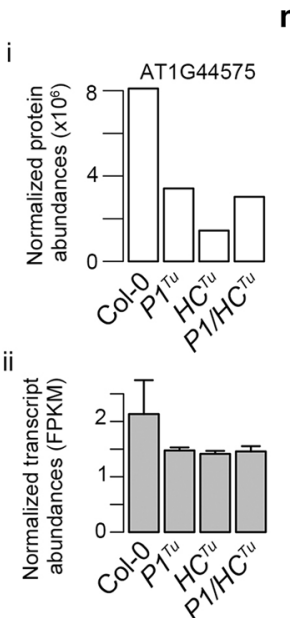
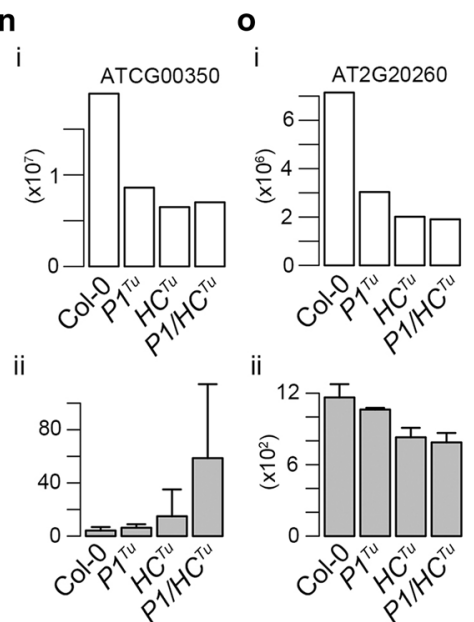
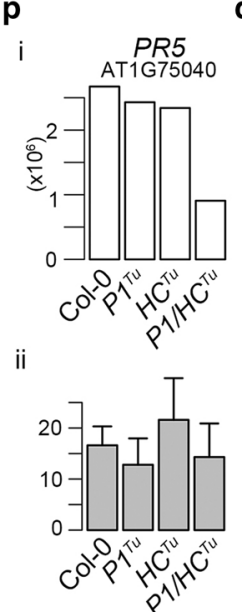
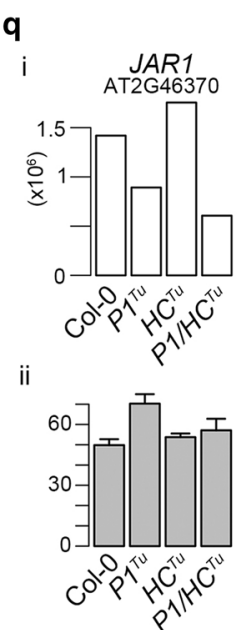

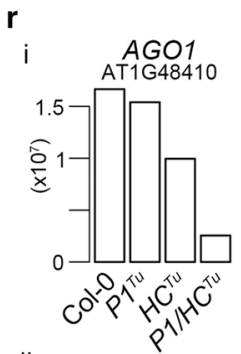

ii

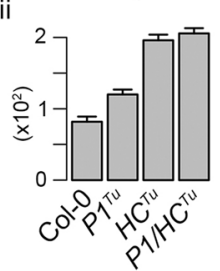

Fig. 4 The protein and transcript levels of critical genes in various transgenic plants. (a-r) Genes that had a significant difference in protein levels (panel ii) between Col-0 and $P 1 / H C^{T u}$ plants were identified and their transcript levels were observed (panel i) in Col-0, $P 1^{T u}, H C^{T u}$, and $P 1 / H C^{\top u}$ plants. The fragments per kilobase of transcript per million (FPKM) were used to represent the normalized transcript expression. The bars represent standard deviations $(n=3)$. Normalized abundances were used to represent the protein amounts 
is induced by methyl jasmonate (MeJA) and triggers endoplasmic reticulum (ER) body formation (Geem et al. 2019; Suzuki et al. 2005). These data indicated that the reduction in the protein levels of APL3, PGL5, and TSA1 occurred in a P1-dependent manner.

Next, we identified differentially expressed proteins between the $H C^{T u}$ and $P 1 / H C^{T u}$ plants. Nine proteins, including 2 superoxide dismutases [SOD1 (AT1G08830), and SOD2 (AT2G28190)], COPPER CHAPERONE FOR SOD1 (CCS1; AT1G12520), and ENHANCED MIRNA ACTIVITY 1/SUPER SENSITIVE TO ABA AND DROUGHT 2 (EMA1/SAD2; AT2G31660), were increased in $P 1 / H C^{T u}$ plants compared with $H C^{T u}$ plants (Fig. 4d-g, panel i). EMA1/SAD2 contains an importinbeta domain and negatively regulates in miRNA activity and is involved in abscisic acid (ABA) signaling (Cui et al. 2016; Panda et al. 2020; Wang et al. 2011).

In contrast, levels of 8 photosystem proteins (ATCG00340, AT1G55670, AT1G31330, AT4G12800, AT1G52230, AT1G44575, ATCG00350, and AT2G20260) were decreased in the $P 1^{T u}, H C^{T u}$, and $P 1 / H C^{T u}$ plants compared with Col-0 (Fig. 4h-o, panel i). However, their transcript levels were not significantly different (Fig. 4h$o$, panel ii). We also found that PATHOGENESISRELATED GENE 5 (PR5; AT1G75040) was decreased in $P 1 / H C^{T u}$ plants compared with Col-0 plants (Fig. 4P, panel i), whereas JASMONATE RESISTANT 1 (JAR1; AT2G46370) was decreased in $P 1^{T u}$ and $P 1 / H C^{T u}$ plants (Fig. 4q, panel i). Similarly, the transcript levels of PR5 and JAR1 were not significantly different between plants (Fig. 4p, q, panel ii). In summary, many instances of posttranslational regulation occurred in the $P 1^{T u}, H C^{T u}$, and $P 1 / H C^{T u}$ plants.

\section{The posttranscriptional and posttranslational regulation of miRNA targets in $P 1 / H C^{\top u}$ plants}

CCS1 is involved in copper delivery, and SOD1 and SOD2 participate in $\mathrm{Cu} / \mathrm{Zn}$ superoxide dismutase activities. The transcripts of these three genes are regulated by miR398 (Bouché 2010; Sunkar et al. 2006). However, there were high levels of CCS1, SOD1, and SOD2 accumulation in the $H C^{T u}$ and $P 1 / H C^{T u}$ plants, which corresponded to their transcript levels, indicating P1/ HC-Pro-mediated PTGS suppression (Fig. 4d-f, panel ii). Indeed, the transcript level of miR168-regulated $A G O 1$ (AT1G48410) was increased in $H C^{T u}$ and $P 1 / H C^{T u}$ plants compared with Col-0 (Fig. 4r, panel ii). Surprisingly, the level of AGO1 protein was decreased via an unknown mechanism in $H C^{T u}$ and $P 1 / H C^{T u}$ plants (Fig. 4r, panel i). The western blot data also indicated that the level of AGO1 was lower in $P 1 / H C^{T u}$ plants than in Col-0 plants but was similar to that in Col-0 plants, $P 1 / H C^{Z y}$ and $P 1 /$ $H C^{T e}$ plants (Fig. 5). These data suggested that the P1/

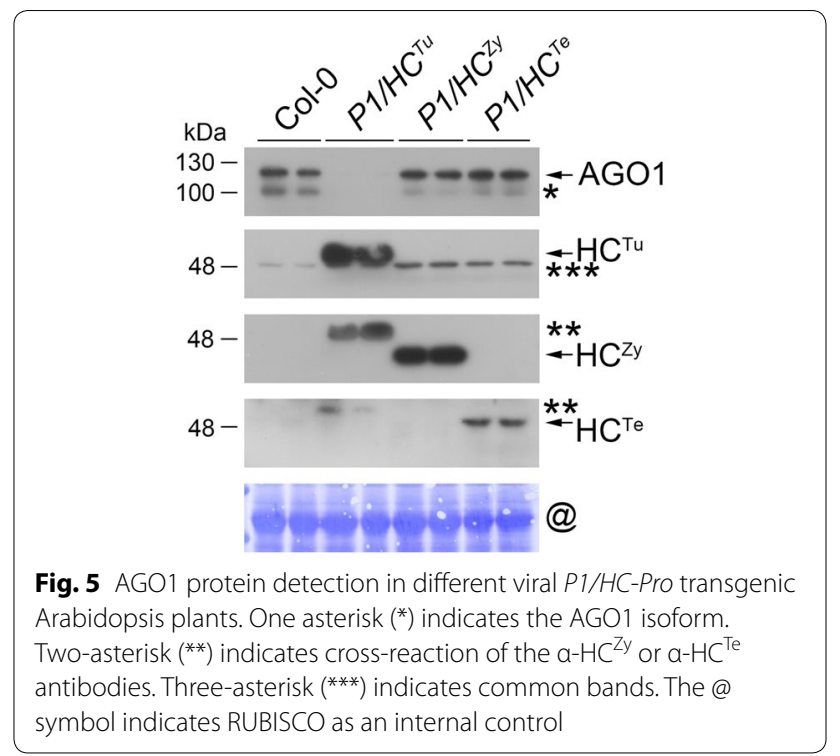

HC-Pro of TuMV has a specific ability to trigger the posttranslational degradation of AGO1.

\section{Comparative gene-to-gene network and transcriptome analysis}

In the transcriptome analysis, we constructed a geneto-gene correlation network to study PTGS suppression from a different perspective. First, we constructed a network for Col-0 vs. P1/HC $C^{T u}$ plants in the ContigViews system. A list of twofold DGEs between Col-0 and P1/ $H C^{T u}$ plants was used to generate a Pearson correlation network (Fig. 6). A group of positive correlations (red lines) and a group of negative correlations (green lines) were highlighted in the network (Fig. 6). The output of the network showed that AGO1, AGO2 (AT1G31280), and AGO3 (AT1G31290) were present in the group of negative correlations (Fig. 6). AGO2 and $A G O 3$ were positively correlated with each other (red line) but had an indirect correlation with AGO1 through XYLOGLUCAN ENDOTRANSGLUCOSYLASE/HYDROLASE 7 (XTH7; AT4G37800) (Fig. 6). Notably, the transcripts of $A G O 1$, $A G O 2$, and $A G O 3$ were upregulated in the $H C^{T u}$ and $P 1 /$ $H C^{T u}$ plants, but the $X T H 7$ transcripts were downregulated, suggesting that the AGOs and XTH7 might have opposite functions in PTGS (Fig. 4r, panel ii; Fig. 8a-c).

Next, we constructed two comparative networks, which were generated by a list of twofold DEGs between Col- 0 and $H C^{T u}$ plants or between Col- 0 and $P 1^{T u}$ plants (Fig. 7a, b). The gene positions in the comparative networks were followed with the Col-0 vs. $P 1 / H C^{T u}$ network for comparison (Figs. 6 and 7). There were 97 genes in the Col-0 vs. P1/HC ${ }^{T u}$ network (Fig. 6); however, there were only 36 genes showed up when we applied the 


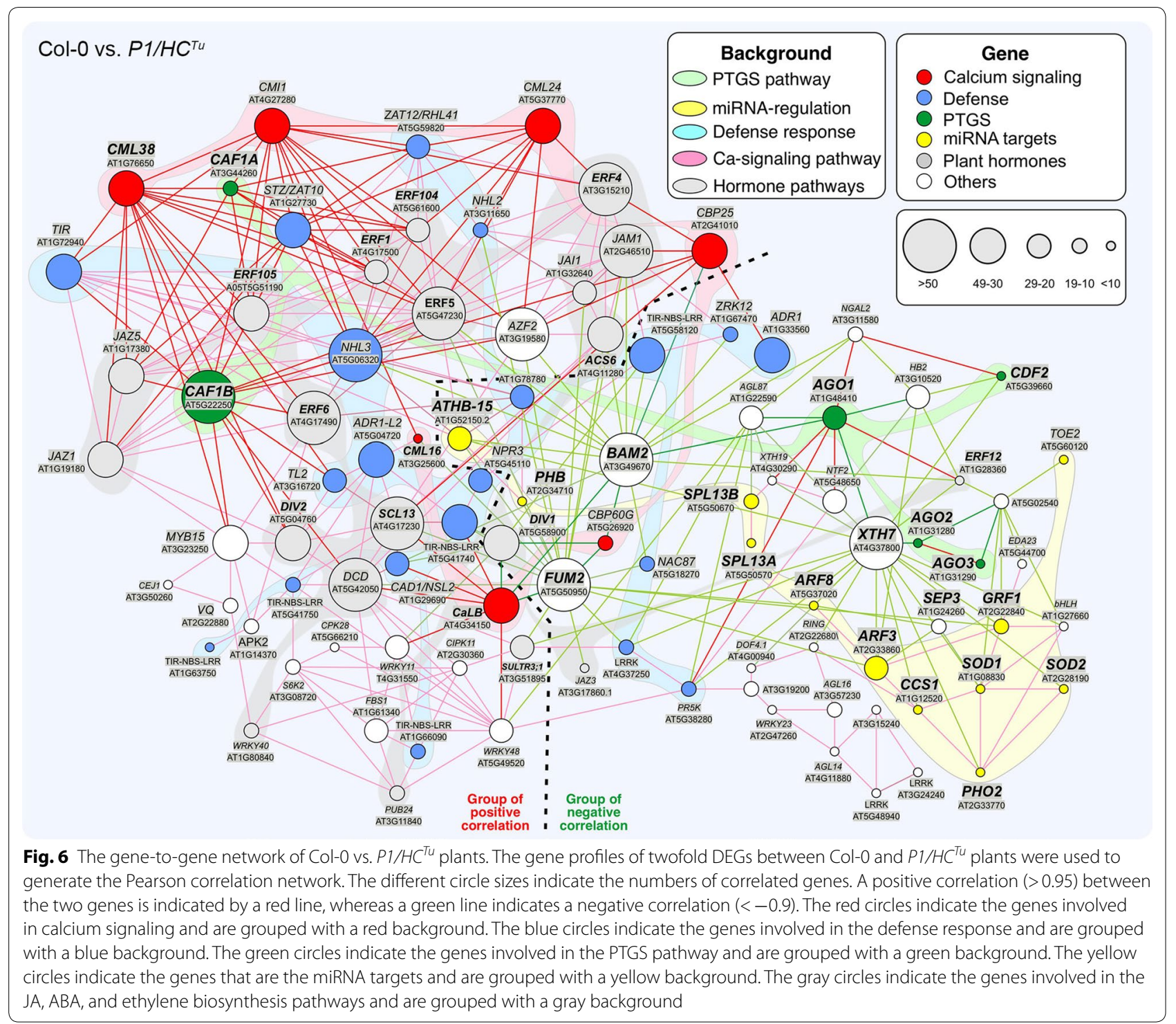

same parameters in the Col-0 vs. $H C^{T u}$ network (Figs. 6 and $7 \mathrm{a}$ ). In addition, the main genes involved in PTGS, such as $A G O 1, A G O 2, A G O 3$, and $X T H 7$, remained in the Col-0 vs. $H C^{T u}$ network (Fig. 7a). This suggested the presence of a basic network backbone in the $\mathrm{HC}^{\mathrm{Tu}}$-mediated PTGS suppression that occurs without the effects of $\mathrm{P} 1^{\mathrm{Tu}}$. In contrast, the Col-0 vs. $P 1^{T u}$ network only had 7 genes in 2 small groups that were also present in parts of the Col- 0 vs. $H C^{T u}$ or Col-0 vs. P1/HC $C^{T u}$ networks (Figs. 6 and 7). Moreover, XTH7 had fewer than 49 connected genes in the Col- 0 vs. $H C^{T u}$ network, whereas $X T H 7$ had 61 connections in the Col-0 vs. P1/HC $C^{T u}$ network (Figs. 6 and 7a). These data indicated that the XTH7 connection is variable in different networks and might play an important role in PTGS suppression. Overall, the comparative network analysis highlights the effects of $\mathrm{P} 1^{\mathrm{Tu}}$ on $\mathrm{HC}^{\mathrm{Tu}}$-mediated PTGS suppression. This also explains why the $P 1 / H C^{T u}$ plant has a severe phenotype because of how many pathways were interfered with.

\section{Critical genes in the Col-0 vs. $P 1 / H C^{T u}$ network that are involved in PTGS}

The importance of $X T H 7$ is not only in the number of gene connections it has or that it is connected with AGO1 and AGO2; XTH7 also had a negative correlation with several miRNA targets in the Col-0 vs. $P 1 / H C^{T u}$ network, such as 2 auxin response transcription factor genes [ARF3 (AT2G33860) and ARF8 (AT5G37020)], PHOSPHATE 2 (PHO2; AT2G33770), GROWTHREGULATING FACTOR 1 (GRF1; AT2G22840), CCS1, 


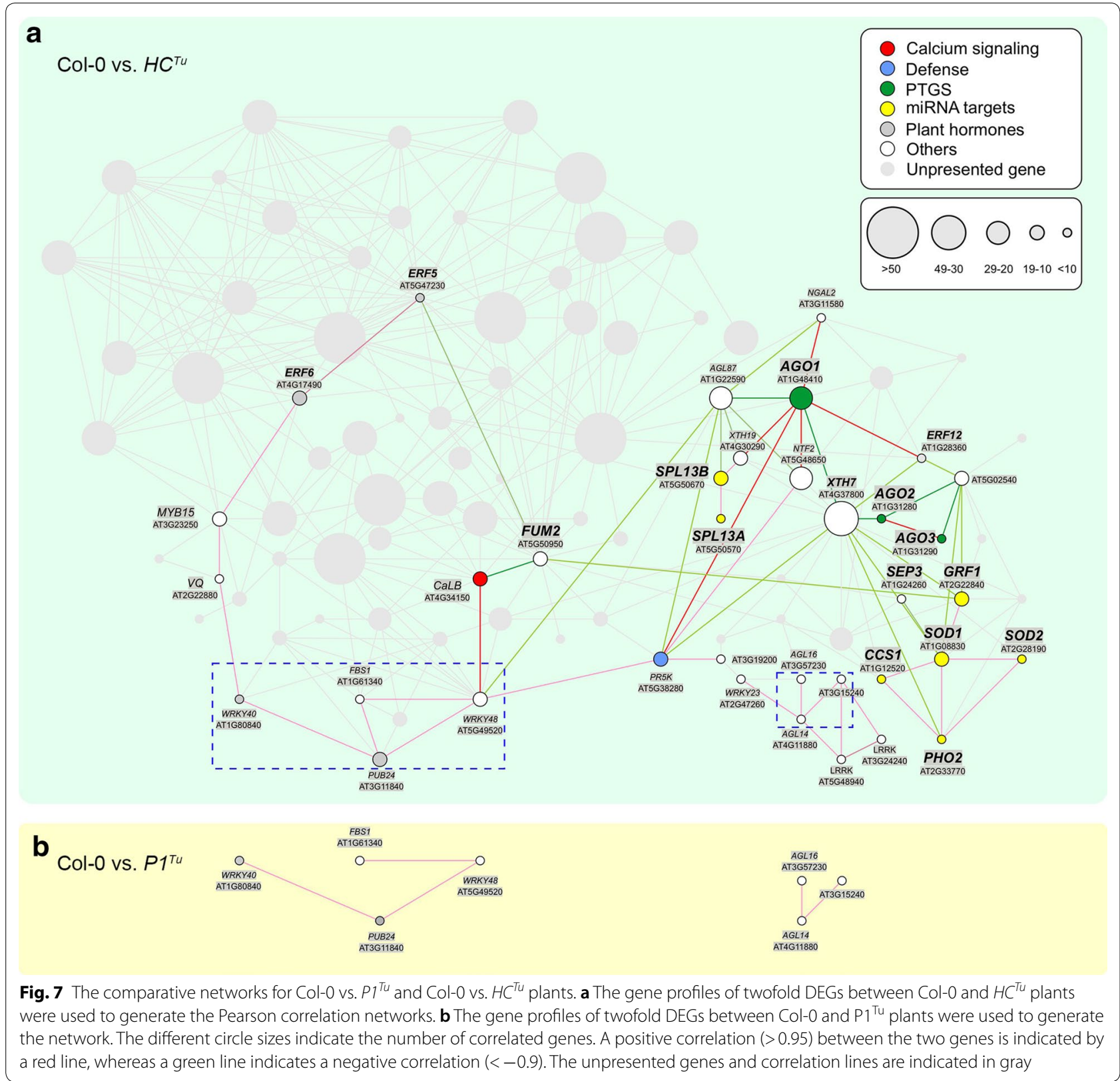

SOD1, and SOD2 (Fig. 5). However, ARF3, ARF8, PHO2, GRF1, CCS1, SOD1, and SOD2 formed a positive correlation in the network (Fig. 6). These miRNA target transcripts were upregulated in $H C^{T u}$ and $P 1 / H C^{T u}$ plants because of PTGS suppression (Fig. 4e-f; panel ii; Fig. 8d-g). Moreover, SEP3 (AT1G24260) showed negative correlations with $X T H 7, A R F 3, A R F 8$, and SOD1 (Fig. 7). In addition, SEP3 transcript levels were lower in $P 1^{T u}, H C^{T u}$, and $P 1 / H C^{T u}$ plants compared to Col-0 plants (Fig. 8h). Notably, SOD1 was shown to have a physical interaction with $\mathrm{P} 1^{\mathrm{Tu}}$ and $\mathrm{P} 1^{\mathrm{Te}}$ (Table 1 ) and was also highlighted in the network, suggesting the importance of SOD1 in PTGS suppression.

Four miRNA targets, including TARGET OF EARLY ACTIVATION TAGGED 2 (TOE2; AT5G60120) and 2 squamosa promoter-binding protein-like genes [SPL13A (AT5G50570), and SPL13B (AT5G50670)], were also found in the group of negative correlation areas, whereas ARABIDOPSIS THALIANA HOMEOBOX PROTEIN 15 (ATHB-15; AT1G52150) and PHABULOSA (PHB; AT2G34710) were found in the boundary between the positive and negative correlation groups (Fig. 6). 


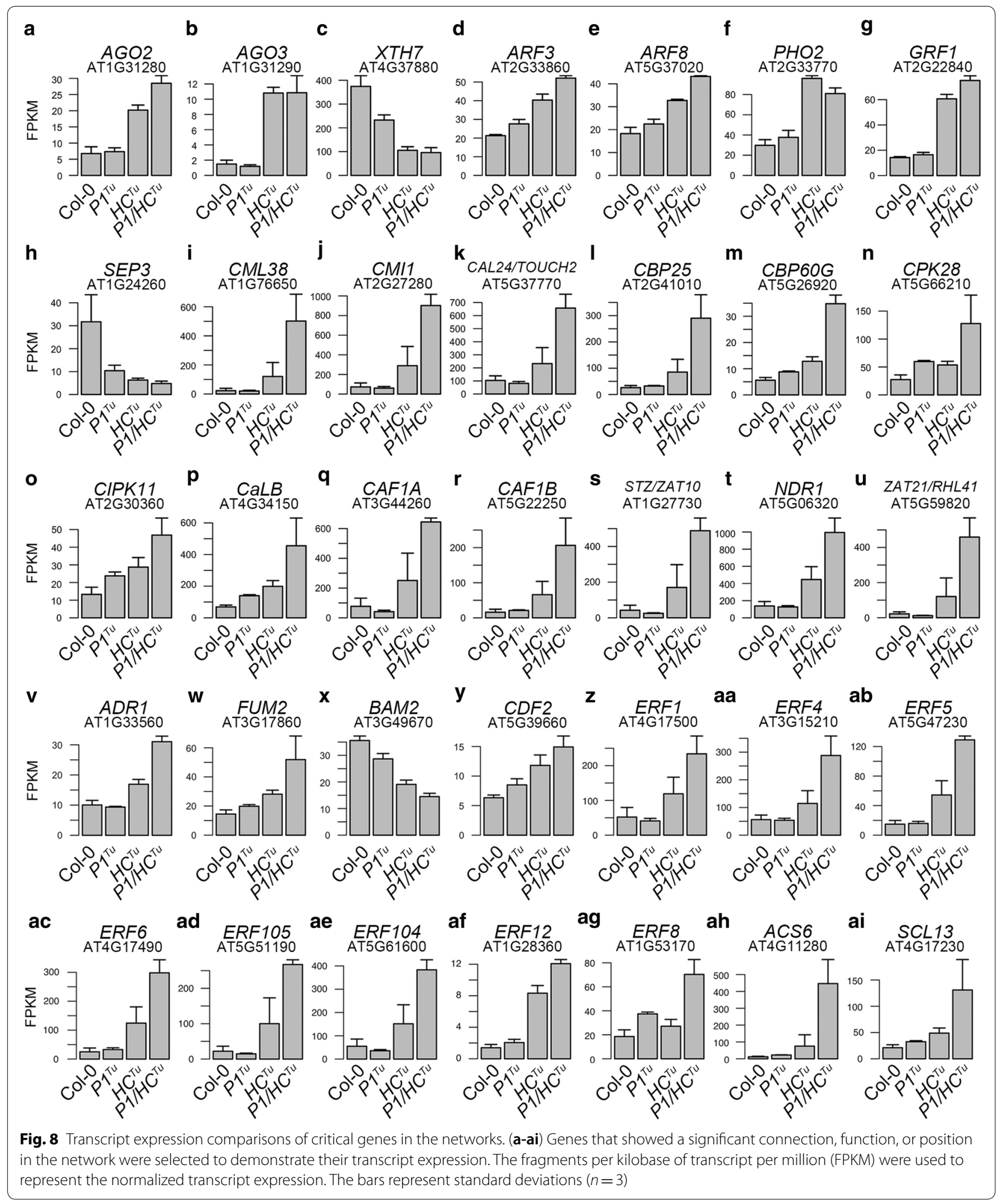


Notably, miR172b regulated TOE2 modules in regulating plant innate immunity (Zou et al. 2018). In the Col-0 vs. P1/HC $C^{T u}$ network, CYCLING DOF FACTOR 2 (CDF2; AT5G39660) and 2 carbon catabolite repressor 4 (CCR4)-associated factor genes [CAF1A (AT3G44260) and $C A F 1 B$ (AT5G22250)] that are involved in RNA regulation were identified in the Col-0 vs. $P 1 / H C^{T u}$ network (Fig. 6). CAF1A and CAF1B catalyze mRNA deadenylation, whereas CDF2 interacts with DCL1 for miRNA biogenesis (Liang et al. 2009; Sun et al. 2015; Walley et al. 2010). These genes were also upregulated in $H C^{T u}$ and $P 1 / H C^{T u}$ plants (Fig. 8q, r, and y).

Eight calcium signaling genes were identified in the group of positive correlations in the network and were significantly upregulated in $P 1 / H C^{T u}$ plants (Figs. 6 and $8 \mathrm{i}-\mathrm{p}$ ). In the network, CALMODULINLIKE 24 (CML24; AT5G37770), and CAM-BINDING PROTWIN 60-LIKE G (CBP60G; AT5G26920) have significant functions in the regulation of autophagy and innate immunity, respectively (Qin et al. 2018; Tsai et al. 2013). In addition, jasmonic acid (JA) signaling and defense genes were highlighted in the positive correlation and their transcripts were upregulated in $H C^{T u}$ and $P 1 / H C^{T u}$ plants (Figs. 6 and $8 \mathrm{q}-\mathrm{v}$ ). In addition, the network indicated that FUMARASE 2 (FUM2; AT5G50950) and BARELY ANY MERISTEM 2 (BAM2; AT3G49670) were present in the boundary region between groups of positive and negative correlation (Fig. 6). BAM2 is a CLAVATA1-related receptor kinase and promotes the differentiation of stem cells on the meristem flank (DeYoung et al. 2006). FUM2 transcripts were upregulated in $H C^{T u}$ and $P 1 / H C^{T u}$ plants, whereas BAM2 transcripts were decreased (Fig. $8 \mathrm{w}$ and $\mathrm{x}$ ). We also showed that $C D F 2$, which is involved in miRNA biogenesis (Sun et al. 2015), is in the negative correlation group and is indirectly connected (negative correlation) to $A G O 1$ through $H B 2$ (AT3G10520) and XTH7 (Fig. 6). The CDF2 transcripts were upregulated in $H C^{T u}$ and $P 1 / H C^{T u}$ plants (Fig. 6y). The functions of critical genes in the Col-0 vs. $P 1 / H C^{T u}$ network are listed in Additional file 3: Table S2.

\section{The auxin, ethylene, and ABA signaling pathways in PTGS suppression}

The auxin response can induce ethylene and concomitantly trigger ABA biosynthesis (Hansen and Grossmann 2000). Importantly, the auxin, ethylene, and ABA signaling genes could be found in the Col-0 vs. P1/ $H C^{T u}$ network (Fig. 6). MiRNA-regulated $A R F 3$ and $A R F 8$ targets are also auxin response genes, which were highly expressed in $H C^{T u}$ and $P 1 / H C^{T u}$ plants (Fig. 8d, e). In contrast, BAM2 expression is antagonistic with auxin transporters (Cecchetti et al. 2015) and its transcripts were downregulated in $H C^{T u}$ and P1/
$H C^{T u}$ plants (Fig. 8x). Ethylene signaling genes, 1-AMINOCYCLOPROPANE-1-CARBOXYLIC ACID (ACC ) SYNTHASE 6 (ACS6; AT4G11280), SCARECROWLIKE 13 (SCL13; AT4G17230), and 8 ethylene responsive element binding factors [ERF1 (AT4G17500), ERF4 (AT3G15210), ERF5 (AT5G47230), ERF6 (AT4G17490), ERF105 (AT5G51190), ERF104 (AT5G61600), ERF12 (AT1G28360), ERF8 (AT1G53170)] were present in the group of positive correlations and their transcripts were upregulated in $H C^{T u}$ and $P 1 / H C^{T u}$ plants (Figs. 6 and $8 \mathrm{z}-$ ai; and Additional file 3: Table S2). Moreover, the results from endogenous ethylene emission experiments showed higher ethylene levels were detected in $P 1 / H C^{T u}$ plants than those in Col-0 plants at each time point (Fig. 9). ABA signaling genes, SULFATE TRANSPORTER 3;1 (SULTR3;1; AT3G51895), and 2 DIVARICATA genes [DIV1 (AT5G58900), and DIV2 (AT5G04760)] were also highlighted in the Col-0 vs. P1/HC $C^{T u}$ network (Fig. 6) (Chen et al. 2019; Fang et al. 2018). These data suggested that P1/HC-Pro-mediated PTGS suppression also interferes with plant hormone signaling pathways.

\section{Discussion}

\section{P1 enhances HC-Pro-mediated PTGS suppression}

In potyvirus, $\mathrm{P} 1$ is a hypervariable protein with poorly understood its function. Previous studies suggested that P1 modulates virus replication, determines pathogenicity in a host-dependent manner, and triggers the host defense response (Maliogka et al. 2012; Pasin et al. 2014). In this study, we demonstrated that 3 viral P1s have a conserved function in enhancing HC-Pro-mediated PTGS suppression. From the perspective of P1-host protein interaction, VIP3/SKI8 turns over the $5^{\prime}$-fragment of RISC-cleaved target RNA, whereas TSN1, TSN2, and VSC are involved in mRNA decapping in stress granules and P-bodies (Branscheid et al. 2015; Deyholos et al. 2003; Gutierrez-Beltran et al. 2015; Sorenson et al. 2018; Xu and Chua 2009). Moreover, a MOS4 modifier, 2

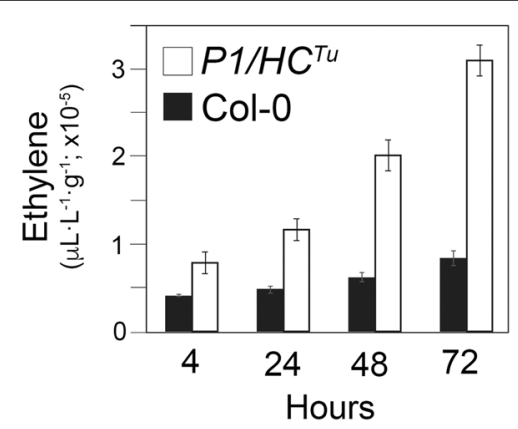

Fig. 9 Time courses of endogenous ethylene detection in Col-0 and P1/HC $C^{\top u}$ plants. The bars represent standard deviations $(n=3)$ 
IMPORTINs, and BIG5, which are involved in RNA splicing and RNA transportation, respectively, also interact with P1 ${ }^{\mathrm{Tu}}$ (Helizon et al. 2018; Kitakura et al. 2017; Luo et al. 2013; Xu et al. 2012). In addition, EMA1/SAD2 contains an importin-beta domain that negatively regulates miRNA activity (Wang et al. 2011). EMA1/SAD2 protein levels were upregulated in $P 1^{T u}, H C^{T u}$, and $P 1 / H C^{T u}$ plants, but their transcript levels did not differ those in Col-0, suggesting P1 stabilized or increases EMA1/SAD2 levels to help inhibit miRNA regulation (Fig. 4g). Moreover, transcriptome data mining also showed that the $C A F 1 A / B$ deadenylases and the $C D F 2$ zinc finger protein had a strong correlation with PTGS suppression. To summarize these findings, posttranscriptional RNA regulation occurs in stress granules and P-bodies, and many RNA regulatory components were identified among the proteins that interacted with P1 or were highlighted in the PTGS suppression network, which suggests that P1 is extremely vital for HC-Pro to enhance suppression.

Although P1 functions in regulating PTGS, it seems that $\mathrm{P} 1$ needs to be generated from the P1/HC-Pro fusion protein to have better enhance HC-Pro suppression. It is a cyclic effect in which lower levels of HC-Pro cause less efficiency in PTGS suppression, resulting in lower levels of HC-Pro. Indeed, the HC-Pro levels of $P 1^{T u} \times H C^{T u}$ (Kan) plants were similar to those of $H C^{T u}$ plants (Fig. 1c), suggesting ectopically expressed P1 did not have the same effect on enhancing HC-Pro as did P1 released from the fusion protein. Why must $\mathrm{P} 1$ be released from the fusion form to enhance HC-Pro ability? It is still unclear.

\section{P1/HC-Pro of TuMV specifically primes posttranslational AGO1 degradation}

AGO1 degradation has been reported to be controlled by selective autophagy (Kobayashi et al. 2019; Li et al. 2019; Michaeli et al. 2019). The P0 viral suppressor of Polerovirus is thought to trigger autophagic AGO1 degradation (Michaeli et al. 2019). In our study, P1/HC-Pro of TuMV specifically triggered AGO1 posttranslational degradation, but the same effect was not observed in $P 1 / H C^{Z y}$ and $P 1 / H C^{T u}$ plants, suggesting that $\mathrm{P} 1 / \mathrm{HC}$-Pro triggering AGO1 degradation does not occur in all potyviruses. In the other words, AGO1 degradation might not be essential for P1/HC-Pro-mediated PTGS suppression.

Autophagy works with vacuoles to allow for the degradation of large protein complexes. VSP29 is involved in the trafficking of vacuolar proteins and in the recycling of vacuolar sorting receptors and specifically interacts with $\mathrm{P} 1^{\mathrm{Tu}}$ (Table 1) (Kang et al. 2012). Moreover, CML24 interacts with AUTOPHAGY GENE 4b (ATG4b), which primes AUTOPHAGY GENE 8 (ATG8) by removing the $\mathrm{C}$-terminus and exposing a glycine residue during autophagy (Tsai et al. 2013). CML24 was found to be present in the group of positive correlations of the PTGS network. Therefore, we implied that P1/HC-Pro of TuMV might also trigger AGO1 posttranslational degradation through autophagy.

\section{Network of HC-Pro-mediated PTGS suppression}

The comparative gene correlation network provides a 4-dimensional perspective, which includes gene expression, gene correlation, position, and time course. This information is helpful to interpret and identify critical genes in pathways of interest. In the Co-0 vs. $H C^{T u}$ network, we identified a basic backbone network in $\mathrm{HC}^{\mathrm{Tu}}$-mediated PTGS suppression. However, the effects of P1-enhanced HC-Pro suppression were highlighted in the Col-0 vs. $P 1 / H C^{T u}$ network upon comparing the two networks. The Col-0 vs. P1/HC ${ }^{T u}$ network specifically highlighted the relationship between AGOs and viral resistance. Previous studies demonstrated that AGO2 and AGO3 upregulated to enhance the viral resistance (Alazem et al. 2017; Harvey et al. 2011; Zheng et al. 2019). AGO2 is a target of miR403, which is negatively regulated by AGO1 (Harvey et al. 2011), suggesting the upregulation of AGO2 in response to AGO1 degradation in $P 1 / H C^{T u}$ plants. However, although we have no explanation for AGO3 upregulation, we assume that the AGO2/AGO3 antiviral system was activated and complemented AGO1 degradation. Indeed, AGO2 and AGO3 are directly positively correlated in the network.

Surprisingly, several miRNA targets, such as CCS1, SOD1, SOD2, PHO2, ARF3, and GFR1, showed a positive correlation in the network. These genes were indirectly negatively correlated with $A G O 1$ through $X T H 7$. In addition, other miRNA targets, such as TOE2, SPL13A/B, $A T H B-15$, and $P H B$ were also present in the network. SPL13A and SPL13B had direct positive correlations. ATHB-15 and PHB, which belong to the homeodomainleucine zipper (HD-ZIP) transcription factor (TF) family, were also positively correlated. To summarize, the gene correlation network had significant accuracy in data mining.

Calcium signaling has been demonstrated to be involved in the suppression of gene silencing (Anandalakshmi et al. 2000; Nakahara et al. 2012). Anandalakshmi et al. (2000) demonstrated that the calmodulin-related protein $(\mathrm{rgs}-\mathrm{CaM})$ in tobacco interacts with $\mathrm{HC}-\mathrm{Pro}$ and that it suppresses gene silencing similar to HC-Pro. Nakahara et al. (2012) demonstrated that tobacco rgsCaM counterattacked various viral suppressors by binding to RNA-binding domains. In addition, rgs-CaM triggers autophagic viral suppressor degradation (Nakahara et al. 2012). Indeed, CML24 has physical interaction 
with ATG4b, suggesting that there is crosstalk between calcium signaling and autophagy (Tsai et al. 2013). CML24 was present in the group with a positive correlation, which was opposite to the AGOs that were present in the group with a negative correlation, suggesting that calcium signaling might counteract gene silencing.

We noted that several genes, such as $X T H 7, F U M 2$, and $B A M 2$, had a significant number of connected genes (>50 connected genes) (Fig. 6). XTH7 has been defined as a xyloglucan endotransglucosylase/hydrolase; however, little is known about its function in PTGS suppression. In addition, the cytosolic fumarase FUM2 is essential for Arabidopsis acclimation to low temperatures (Dyson et al. 2016). BAM2 is a CLAVATA1-related receptor kinase, and a little is known about its involvement in anther and meristem development (DeYoung et al. 2006; Hord et al. 2006). Although the functions of these genes were not explicitly linked with PTGS or defense, they were present in critical positions within the network with a large number of connected genes, which provides information for future research directions to investigate PTGS.

\section{Auxin and ethylene signaling in the serrated leaf phenotype}

Current studies have indicated that the treatment with a high dose of auxin elicits endogenous ethylene production. In $P 1 / H C^{T u}$ plants, 3 auxin signaling genes (ARF3, $A R F 8$, and SUTR3;1) were upregulated; therefore, we assume that ethylene was accumulated along with the increased expression of ethylene signaling genes. In addition, Hay et al. (2006) demonstrated that auxin can initiate marginal serrations in leaves, suggesting that the serrated leaf phenotype of $P 1 / H C^{T u}$ plants might be related to endogenous auxin accumulation.

\section{Conclusion}

In this study, we used a transgenic plant approach to investigate the functions of $\mathrm{P} 1$ and $\mathrm{HC}$-Pro. By mining high-throughput data from proteomic and transcriptomic profiles, P1-interacting proteins and critical genes in PTGS suppression were identified. Instead of traditional DEG identification, the comparative gene correlation network provides a four-dimensional perspective to identify critical genes, and provides new ideas and directions for further investigation. We believe plant molecular viology and plant molecular biology, like two hands, can be used together to efficiently investigate the PTGS mechanism.

\section{Supplementary information}

Supplementary information accompanies this paper at https://doi. org/10.1186/s40529-020-00299-x.

Additional file 1. The profiles of protemoics.

Additional file 2: Table S1. The P1 interacting proteins.

Additional file 3: Table S2. Critical genes in Col-0 vs. $P 1 / H C^{R}$ network.

\section{Abbreviations}

ABA: Abscisic acid; ACC: 1-Aminocyclopropane-1-carboxylic acid; ACS6: 1-Aminocyclopropane-1-carboxylic acid synthase 6; AGC: Automatic gain control; AP2: Apetala 2; APL3: ADP-glucose pyrophosphorylase 3; ARF3: Auxin response transcription factor gene 3; ARF8: Auxin response transcription factor gene 8; ATG4b: Autophagy gene 4b; ATG8: Autophagy gene 8; ATHB-15: Arabidopsis thaliana homeobox protein 15; BAM2: Barely any meristem 2; BIG5: Brefeldin A-inhibited guanine nucleotide-exchange protein 5; CAF1A: Carbon catabolite repressor 4 (CCR4)-associated factor gene 1A; CAF1B: Carbon catabolite repressor 4 (CCR4)-associated factor gene 1B; CBP60G: Cam-binding protwin 60-like G; CCS1: Copper chaperone for SOD1; CDF2: Cycling dof factor 2; CML24: Calmodulin-like 24; Col-0: Columbia; DCL1: Dicer-like 1; DCL2: Dicerlike 2; DCL4: Dicer-like 4; DEG: Differentially expressed genes; DIV1: DIVARICATA gene 1; DIV2: DIVARICATA gene 2; DTT: Dithiothreitol; EMA1/SAD2: Enhanced MIRNA activity 1/super sensitive to ABA and drought 2; ER: Endoplasmic reticulum; ERF: Ethylene responsive element binding factors; FID: Flame ionization detector; FPKM: Fragments per kilobase of transcript per million; FPLC: Fast protein liquid chromatography; FUM2: FUMARASE 2; GRF1: Growth-regulating factor 1; HD-ZIP: Homeodomain-leucine zipper; IAA: lodoacetamide; ID: Inner diameter; IP: Immunoprecipitation; JA: Jasmonic acid; JAR1: Jasmonate resistant 1; MeJA: Methyl jasmonate; miRNA: microRNA; MOS4: Modifier of SNC1: 4; MS: Murashige and Skoog; NUA: Nuclear-pore anchor; OPPP: Oxidative pentose-phosphate pathway; P-bodies: Processing bodies; PCR: Polymerase chain reaction; PD: Proteome discoverer; PGL5: 6-phosphogluconolactonase 5; PHB: Phabulosa; PHO2: Phosphate 2; PR5: Pathogenesis-related gene 5; PTGS: Posttranscriptional gene silencing; rgs-CaM: Calmodulin-related protein; RISC: RNA-induced silencing complex; SCL13: Scarecrow-like 13; siRNA: Shortinterfering RNA; SOD1: Superoxide dismutase 1; SOD2: Superoxide dismutase 2; SPL13A: Squamosa promoter-binding protein-like gene 13A; SPL13B: Squamosa promoter-binding protein-like gene 13B; SULTR3;1: Sulfate transporter 3;1; SVP: Short vegetative phase; TEV: Tobacco etch virus; TF: Transcription factor; TOE2: Target of early activation tagged 2; TSA1: Tonsoku (TSK)-associating protein 1;TSN1:TUDOR-SN ribonucleases 1; TSN2:TUDOR-SN ribonucleases 2; TuMV: Turnip mosaic virus; VIP3/SKI8: Vernalization Independence 3/superkiller 8; VSC: Varicose; VSP29: Vacuolar protein sorting-associated protein 29; XTH7: Xyloglucan endotransglucosylase/hydrolase 7; ZYMV: Zucchini yellow mosaic virus.

\section{Acknowledgements}

We acknowledge the mass spectrometry technical research services from the National Taiwan University Consortia of Key Technologies and National Taiwan University Instrumentation Center and deep sequencing from the High

Throughput Sequencing Core of Academia Sinica.

\section{Authors' contributions}

SFH performed the experiments; WLW, RYF, HPW and HFL contributed the transcriptome database and network analysis; SFH produced AGO1 antibodies; HYW performed proteomics analysis; PCL observed AGO1 degradation by western blot; MS and CTW performed ethylene detection; SFH, NS, and SSL contributed to experimental design and wrote the paper. All authors read and approved the final manuscript.

\section{Funding}

This study was supported by the cooperation funding of $\mathrm{CH}$ Biotech company (08HT654004) and Council of Agriculture (109A3031). This article was subsidized by the Ministry of Science and Technology and National Taiwan University (NTU), Taiwan 


\section{Availability of data and materials}

All data generated or analyzed in this study are in this published article.

\section{Ethics approval and consent to participate}

Not applicable.

\section{Consent for publication}

Not applicable.

\section{Competing interests}

The authors declare that they have no competing interests.

\section{Author details}

${ }^{1}$ Institute of Biotechnology, National Taiwan University, Taipei 106, Taiwan. ${ }^{2}$ Agricultural Biotechnology Research Center, Academia Sinica, Taipei 115, Taiwan. ${ }^{3}$ Center of Biotechnology, National Taiwan University, Taipei 106, Taiwan. ${ }^{4}$ Instrumentation Center, National Taiwan University, Taipei 106, Taiwan. ${ }^{5}$ Department of Horticulture and Landscape Architecture, National Taiwan University, Taipei 106, Taiwan.

Received: 29 April 2020 Accepted: 16 July 2020

Published online: 03 August 2020

\section{References}

Agudelo-Romero P, de la Iglesia F, Elena SF (2008) The pleiotropic cost of hostspecialization in Tobacco etch potyvirus. Infect Genet Evol 8:806-814

Alazem M, He MH, Moffett P, Lin NS (2017) Abscisic acid induces resistance against Bamboo mosaic virus through Argonaute2 and 3. Plant Physiol 174:339-355

Anandalakshmi R, Pruss GJ, Ge X, Marathe R, Mallory AC, Smith TH, Vance VB (1998) A viral suppressor of gene silencing in plants. Proc Natl Acad Sci USA 95:13079-13084

Anandalakshmi R, Marathe R, Ge X, Herr JMJ, Mau C, Mallory A, Pruss G, Bowman L, Vance VB (2000) A calmodulin-related protein that suppresses posttranscriptional gene silencing in plants. Science 290:142-144

Bouché N (2010) New insights into miR398 functions in Arabidopsis. Plant Signal Behav 5:684-686

Branscheid A, Marchais A, Schott G, Lange H, Gagliardi D, Andersen SU, Voinnet O, Brodersen P (2015) SKI2 mediates degradation of RISC 5'-cleavage fragments and prevents secondary siRNA production from miRNA targets in Arabidopsis. Nucleic Acids Res 43:10975-10988

Cecchetti V, Brunetti P, Napoli N, Fattorini L, Altamura MM, Costantino P, Cardarelli $M$ (2015) $A B C B 1$ and $A B C B 19$ auxin transporters have synergistic effects on early and late Arabidopsis anther development. J Integr Plant Biol 57:1089-1098

Chen Z, Zhao PX, Miao ZQ, Qi GF, Wang Z, Yuan Y, Ahmad N, Cao MJ, Hell R, Wirtz M, Xiang CB (2019) SULTR3s function in chloroplast sulfate uptake and affect $\mathrm{ABA}$ biosynthesis and the stress response. Plant Physiol 180:593-604

Chiu MT, Lin CP, Lin PC, Lin SS (2013) Enhance of IgG purification by FPLC for a serological study on the Turnip mosaic virus P1 Protein. Plant Path Bull 22:21-30

Cui Y, Fang X, Qi Y (2016) TRANSPORTIN1 promotes the association of microRNA with ARGONAUTE1 in Arabidopsis. Plant Cell 28:2576-2585

Deyholos MK, Cavaness GF, Hall B, King E, Punwani J, Van Norman J, Sieburth LE (2003) VARICOSE, a WD-domain protein, is required for leaf blade development. Development 130:6577-6588

DeYoung BJ, Bickle KL, Schrage KJ, Muskett P, Patel K, Clark SE (2006) The CLAVATA1-related BAM1, BAM2 and BAM3 receptor kinase-like proteins are required for meristem function in Arabidopsis. Plant J 45:1-16

Dyson BC, Miller MA, Feil R, Rattray N, Bowsher CG, Goodacre R, Lunn JE, Johnson GN (2016) FUM2, a cytosolic fumarase, is essential for acclimation to low temperature in Arabidopsis thaliana. Plant Physiol 172:118-127

Fang Q, Wang Q, Mao H, Xu J, Wang Y, Hu H, He S, Tu J, Cheng C, Tian G, Wang X, Liu X, Zhang C, Luo K (2018) AtDIV2, an R-R-type MYB transcription factor of Arabidopsis, negatively regulates salt stress by modulating ABA signaling. Plant Cell Rep 37:1499-1511

Geem KR, Kim DH, Lee DW, Kwon Y, Lee J, Kim JH, Hwang I (2019) Jasmonic acid-inducible TSA1 facilitates ER body formation. Plant J 97:267-280
Gutierrez-Beltran E, Moschou PN, Smertenko AP, Bozhkov PV (2015) Tudor staphylococcal nuclease links formation of stress granules and processing bodies with mRNA catabolism in Arabidopsis. Plant Cell 27:926-943

Hansen H, Grossmann K (2000) Auxin-induced ethylene triggers abscisic acid biosynthesis and growth inhibition. Plant Physiol 124:1437-1448

Harvey JJ, Lewsey MG, Patel K, Westwood J, Heimstädt S, Carr JP, Baulcombe DC (2011) An antiviral defense role of AGO2 in plants. PLOS ONE 6:e14639

Hay A, Barkoulas M, Tsiantis M (2006) ASYMMETRIC LEAVES1 and auxin activities converge to repress BREVIPEDICELLUS expression and promote leaf development in Arabidopsis. Development 133:3955-3961

Helizon H, Rösler-Dalton J, Gasch P, von Horsten S, Essen LO, Zeidler M (2018) Arabidopsis phytochrome A nuclear translocation is mediated by a farred elongated hypocotyl 1-importin complex. Plant J 96:1255-1268

Hord CL, Chen C, Deyoung BJ, Clark SE, Ma H (2006) The BAM1/BAM2 receptor-like kinases are important regulators of Arabidopsis early anther development. Plant Cell 18:1667-1680

Kang H, Kim SY, Song K, Sohn EJ, Lee Y, Lee DW, Hara-Nishimura I, Hwang I (2012) Trafficking of vacuolar proteins: the crucial role of Arabidopsis vacuolar protein sorting 29 in recycling vacuolar sorting receptor. Plant Cell 24:5058-5073

Kasschau KD, Carrington JC (1998) A counterdefensive strategy of plant viruses: suppression of posttranscriptional gene silencing. Cell 95:461-470

Kasschau KD, Xie Z, Allen E, Llave C, Chapman EJ, Krizan KA, Carrington JC (2003) P1/HC-Pro, a viral suppressor of RNA silencing, interferes with Arabidopsis development and miRNA unction. Dev Cell 4:205-217

Kitakura S, Adamowski M, Matsuura Y, Santuari L, Kouno H, Arima K, Hardtke CS, Friml J, Kakimoto T, Tanaka H (2017) BEN3/BIG2 ARF GEF is involved in brefeldin A-sensitive trafficking at the trans-Golgi network/early endosome in Arabidopsis thaliana. Plant Cell Physiol 58:1801-1811

Kobayashi H, Shoji K, Kiyokawa K, Negishi L, Tomari Y (2019) VCP machinery mediates autophagic degradation of empty argonaute. Cell Rep 28:1144-1153

Kung YJ, Lin PC, Yeh SD, Hong SF, Chua NH, Liu LY, Lin CP, Huang YH, Wu HW, Chen CC, Lin SS (2014) Genetic analyses of the FRNK motif function of Turnip mosaic virus uncover multiple and potentially interactive pathways of cross-protection. Mol Plant Microbe Interact 27:944-955

Lansing H, Doering L, Fischer K, Baune MC, Schaewen AV (2020) Analysis of potential redundancy among Arabidopsis 6-phosphogluconolactonase isoforms in peroxisomes. J Exp Bot 71:823-836

Li Y, Sun Q, Zhao T, Xiang H, Zhang X, Wu Z, Zhou C, Zhang X, Wang Y, Zhang Y, Wang X, Li D, Yu J, Dinesh-Kumar SP, Han C (2019) Interaction between Brassica yellows virus silencing suppressor P0 and plant SKP1 facilitates stability of $\mathrm{PO}$ in vivo against degradation by proteasome and autophagy pathways. New Phytol 222:1458-1473

Liang W, Li C, Liu F, Jiang H, Li S, Sun J, Wu X, Li C (2009) The Arabidopsis homologs of CCR4-associated factor 1 show mRNA deadenylation activity and play a role in plant defence responses. Cell Res 19:307-316

Liu K, Zou W, Gao X, Wang X, Yu Q, Ge L (2019) Young seedlings adapt to stress by retaining starch and retarding growth through ABA-Dependent and -independent pathways in Arabidopsis. Biochem Biophys Res Commun 515:699-705

Luo Y, Wang Z, Ji H, Fang H, Wang S, Tian L, Li X (2013) An Arabidopsis homolog of importin $\beta 1$ is required for $A B A$ response and drought tolerance. Plant J 75:377-389

Maliogka VI, Salvador B, Carbonell A, Sáenz P, León DS, Oliveros JC, Delgadillo MO, García JA, Simón-Mateo C (2012) Virus variants with differences in the P1 protein coexist in a Plum pox virus population and display particular host-dependent pathogenicity features. Mol Plant Pathol 13:877-886

Martínez F, Daròs JA (2014) Tobacco etch virus protein P1 traffics to the nucleolus and associates with the host 605 ribosomal subunits during infection. J Virol 88:10725-10737

Michaeli S, Clavel M, Lechner E, Viotti C, Wu J, Dubois M, Hacquard T, Derrien B, Izquierdo E, Lecorbeiller M, Bouteiller N, De Cilia J, Ziegler-Graff V, Vaucheret H, Galili G, Genschik P (2019) The viral F-box protein P0 induces an ER-derived autophagy degradation pathway for the clearance of membrane-bound AGO1. Proc Natl Acad Sci USA 116:22872-22883

Nakahara KS, Masuta C, Yamada S, Shimura H, Kashihara Y, Wada TS, Meguro A, Goto K, Tadamura K, Sueda K, Sekiguchi T, Shao J, Itchoda N, Matsumura T, Igarashi M, Ito K, Carthew RW, Uyeda I (2012) Tobacco calmodulin-like 
protein provides secondary defense by binding to and directing degradation of virus RNA silencing suppressors. Proc Natl Acad Sci USA 109:10113-10118

Niu QW, Lin SS, Reyes JL, Chen KC, Wu HW, Yeh SD, Chua NH (2006) Expression of artificial microRNAs in transgenic Arabidopsis thaliana confers virus resistance. Nat Biotechnol 2006:1420-1428

Orban TI, Izaurralde E (2005) Decay of mRNAs targeted by RISC requires XRN1, the Ski complex, and the exosome. RNA 11:459-469

Panda C, Li X, Wager A, Chen HY, Li X (2020) An importin-beta-like protein mediates lignin-modification-induced dwarfism in Arabidopsis. Plant J. https://doi.org/10.1111/tpj.14701

Pasin F, Simón-Mateo C, García JA (2014) The hypervariable amino-terminus of P1 protease modulates potyviral replication and host defense responses. PLoS Pathog 10:e1003985

Qin J, Wang K, Sun L, Xing H, Wang S, Li L, Chen S, Guo HS, Zhang J (2018) The plant-specific transcription factors CBP60g and SARD1 are targeted by a Verticillium secretory protein VdSCP41 to modulate immunity. Elife 7:e34902

Silhavy D, Molnár A, Lucioli A, Szittya G, Hornyik C, Tavazza M, Burgyán J (2002) A viral protein suppresses RNA silencing and binds silencing-generated, 21- to 25-nucleotide double-stranded RNAs. EMBO J 21:3070-3080

Sorenson RS, Deshotel MJ, Johnson K, Adler FR, Sieburth LE (2018) Arabidopsis mRNA decay landscape arises from specialized RNA decay substrates, decapping-mediated feedback, and redundancy. Proc Natl Acad Sci USA 115:E1485-E1494

Sun Z, Guo T, Liu Y, Liu Q, Fang Y (2015) The roles of Arabidopsis CDF2 in transcriptional and posttranscriptional regulation of primary microRNAs. PLoS Genet 11:e1005598

Sunkar R, Kapoor A, Zhu JK (2006) Posttranscriptional induction of two Cu/Zn superoxide dismutase genes in Arabidopsis is mediated by downregulation of miR398 and important for oxidative stress tolerance. Plant Cell 18:2051-2065

Suzuki T, Nakajima S, Inagaki S, Hirano-Nakakita M, Matsuoka K, Demura T, Fukuda H, Morikami A, Nakamura K (2005) TONSOKU is expressed in S phase of the cell cycle and its defect delays cell cycle progression in Arabidopsis. Plant Cell Physiol 46:736-742

Tsai YC, Koo Y, Delk NA, Gehl B, Braam J (2013) Calmodulin-related CML24 interacts with ATG4b and affects autophagy progression in Arabidopsis. Plant J 73:325-335

Valli A, Martín-Hernández AM, López-Moya JJ, García JA (2006) RNA silencing suppression by a second copy of the P1 serine protease of Cucumber vein yellowing ipomovirus, a member of the family Potyviridae that lacks the cysteine protease HCPro. J Virol 80:10055-10063

Walley JW, Kelley DR, Nestorova G, Hirschberg DL, Dehesh K (2010) Arabidopsis deadenylases AtCAF1a and AtCAF1b play overlapping and distinct roles in mediating environmental stress responses. Plant Physiol 152:866-875

Wang W, Ye R, Xin Y, Fang X, Li C, Shi H, Zhou X, Qi Y (2011) An importin $\beta$ protein negatively regulates MicroRNA activity in Arabidopsis. Plant Cell 23:3565-3576

Wu HW, Lin SS, Chen KC, Yeh SD, Chua NH (2010) Discriminating mutations of HC-Pro of Zucchini yellow mosaic virus with differential effects on small RNA pathways involved in viral pathogenicity and symptom development. Mol Plant Microbe Interact 23:17-28

Xu J, Chua NH (2009) Arabidopsis decapping 5 is required for mRNA decapping, P-body formation, and translational repression during postembryonic development. Plant Cell 21:3270-3279

Xu F, Xu S, Wiermer M, Zhang Y, Li X (2012) The cyclin L homolog MOS12 and the MOS4-associated complex are required for the proper splicing of plant resistance genes. Plant J 70:916-928

Xue S, Zou J, Liu Y, Wang M, Zhang C, Le J (2019) Involvement of BIG5 and BIG3 in BRI1 Trafficking Reveals Diverse Functions of BIG-subfamily ARF-GEFs in Plant Growth and Gravitropism. Int J Mol Sci. https://doi.org/10.3390/ ijms20092339

Yan C, Yan Z, Wang Y, Yan X, Han Y (2014) Tudor-SN, a component of stress granules, regulates growth under salt stress by modulating GA200x3 mRNA levels in Arabidopsis. J Exp Bot 65:5933-5944

Zhang X, Yuan YR, Pei Y, Lin SS, Tuschl T, Patel DJ, Chua NH (2006) Cucumber mosaic virus-encoded 2b suppressor inhibits Arabidopsis Argonaute1 cleavage activity to counter plant defense. Genes Dev 20:3255-3268

Zheng X, Fahlgren N, Abbasi A, Berry JC, Carrington JC (2019) Antiviral ARGONAUTEs against Turnip Crinkle Virus revealed by image-based trait analysis. Plant Physiol 180:1418-1435

Zou Y, Wang S, Zhou Y, Bai J, Huang G, Liu X, Zhang Y, Tang D, Lu D (2018) Transcriptional regulation of the immune receptor FLS2 controls the ontogeny of plant innate immunity. Plant Cell 30:2779-2794

\section{Publisher's Note}

Springer Nature remains neutral with regard to jurisdictional claims in published maps and institutional affiliations.

\section{Submit your manuscript to a SpringerOpen ${ }^{\circ}$ journal and benefit from:}

- Convenient online submission

- Rigorous peer review

- Open access: articles freely available online

- High visibility within the field

Retaining the copyright to your article

Submit your next manuscript at $\boldsymbol{\nabla}$ springeropen.com 